\title{
REGENERAÇÃO HEPÁTICA EM BAGRE AFRICANO (CLARIAS gariepinus) APÓS HEPATECTOMIA PARCIAL
}

\section{NILTON PEDRO DOS SANTOS}

Dissertação de Mestrado depositada na Seção de Pós-Graduação da Faculdade de Zootecnia e Engenharia de Alimentos da USP, como parte dos requisitos para a obtenção do Título de Mestre em Zootecnia, na área de Concentração: Qualidade e Produtividade Animal.

Orientador: Prof. Dr. FRANCISCO JAVIER HERNANDEZ BLAZQUEZ 
À minha Mãe APARECIDA AMÉRICA DOS SANTOS, por ser uma constante em minha vida, mesmo não estando mais entre nós. 
Ao Prof. Dr. FRANCISCO JAVIER HERNANDEZ BLAZQUEZ pela competência profissional e pela capacidade e paciência na minha orientação 
Agradecimentos

Ao Prof. Dr. FRANCISCO JAVIER HERNANDEZ BLAZQUEZ, pela eficiente orientação e incentivo

À Fundação de Amparo à Pesquisa do Estado de São Paulo (FAPESP), por ter concedido recursos para a realização deste trabalho

Ao Prof. Dr. JOSE BENTO STERMAN FERRAZ, pelo incentivo e pela luta para que esta dissertação e a de outros funcionários pudessem ser realizadas

Ao Prof. Dr. ANTONIO AUGUSTO MENDES MAIA, pelo incentivo e conselhos úteis durante a fase experimental

Ao Prof. Dr. FLAVIO VIEIRA MEIRELLES, pela força e constante incentivo

Ao RICARDO ROMÃO GUERRA, pela colaboração do princípio ao fim deste trabalho

Às amigas e companheiras de jornada GIOVANA KREMPEL FONSECA MERIGHE P SANDRA APARECIDA DE OLIVEIRA pelo apoio e incentivo constante

Aos amigos do ZAB pela força

À Comissão de Pós Graduação da FZEA 


\section{INTRODUÇÃO}

2. MATERIAIS E MÉTODOS --_- 5

2.1. CIRURGIA------on

2.2. DETERMINAÇÃO DA CONCENTRAÇÃO ÓTIMA DE BRDU------------ 6

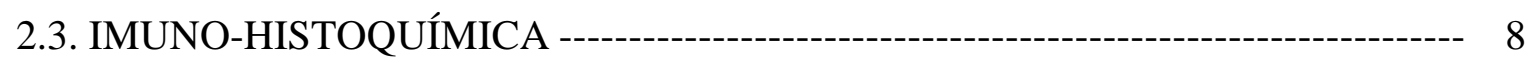

2.3.1. BRDU ----- 8

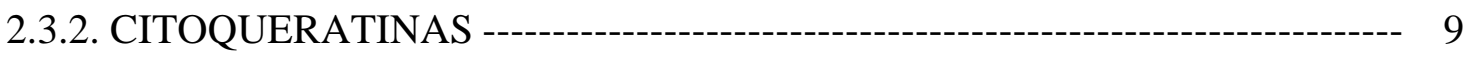

2.3.3. DUCTOS BILIARES ---_-_-- 10

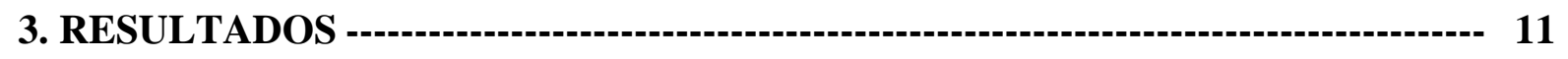

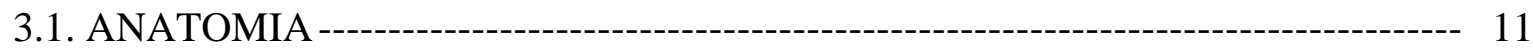

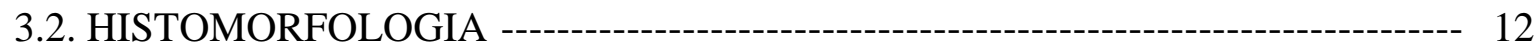

3.3. HEPATECTOMIA DE 30\% ---_- 15

3.3.1. MODIFICAÇÕES HISTOLÓGICAS --_-- 15

3.3.2. ÍNDICE DE PROLIFERAÇÃO CELULA MEDIDO PELA BRDU---------- 17

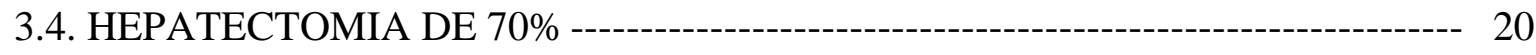

3.4.1. MODIFICAÇÕES HISTOLÓGICAS --------------------------------- 20

3.4.2. ÍNDICE DE PROLIFERAÇÃO CELULA MEDIDO PELA BRDU---------- 20

3.5. DUCTOS BILIARES ---_- 23

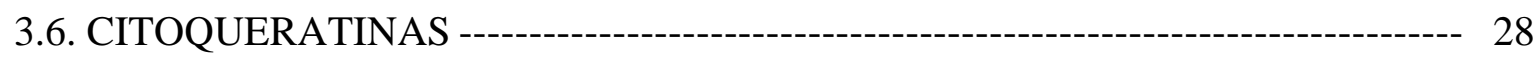

3.6.1. HEPATECTOMIA DE 30\% --- 28

3.6.2. HEPATECTOMIA DE 70\% ---_-- 32

4. DISCUSSÃO -- 35

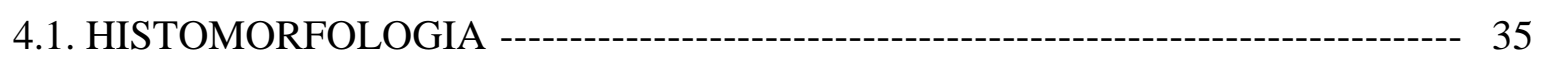



4.3. DUCTOS BILIARES -----o- 41

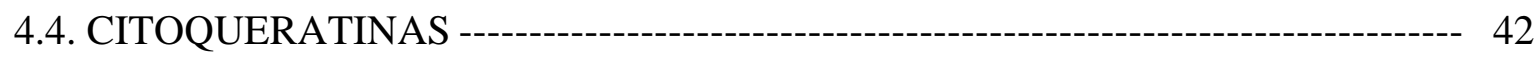

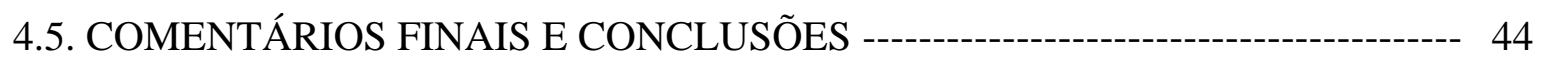

5. CONCLUSÕES -

6. REFERÊNCIAS BIBLIOGRÁFICAS --1.-- 48 


\section{Lista de Figuras}

Figura 1 -------------------------------------------------------------------------------------------------------- 11

Figura 2 ----------------------------------------------------------------------------------------------------- 14

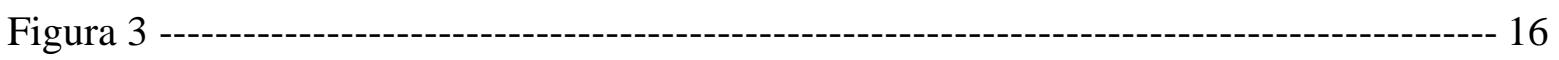

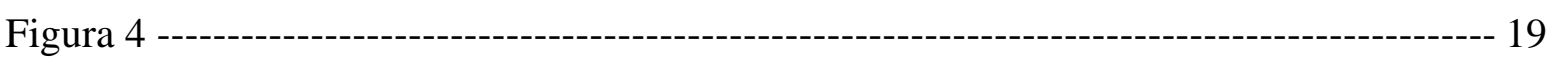

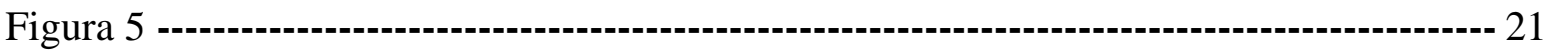

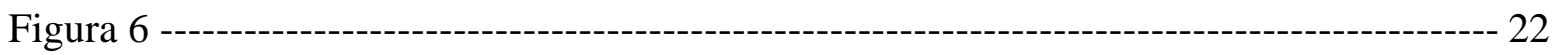

Figura 7 ------------------------------------------------------------------------------------------------------- 25

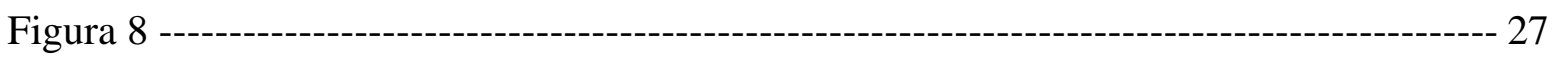

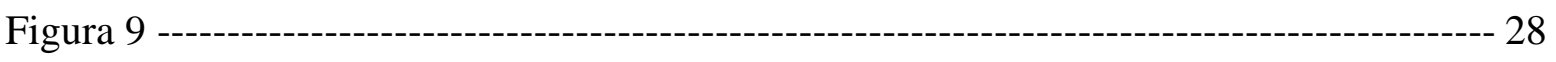

Figura 10 ------------------------------------------------------------------------------------------------------ 30

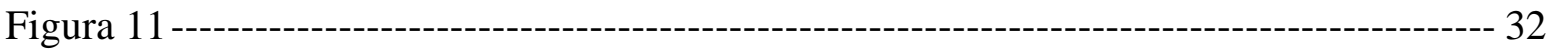

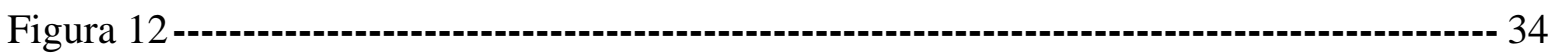


Lista de Tabelas

Tabela I ------------------------------------------------------------------------------------------------------ 7

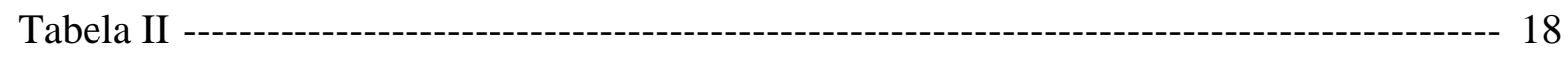

Tabela III -------------------------------------------------------------------------------------------------- 18

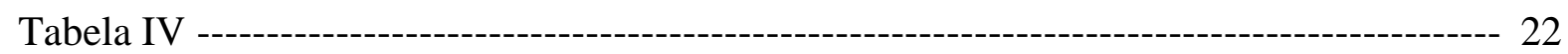

Tabela V ------------------------------------------------------------------------------------------------ 26

Tabela VI ------------------------------------------------------------------------------------------------- 26

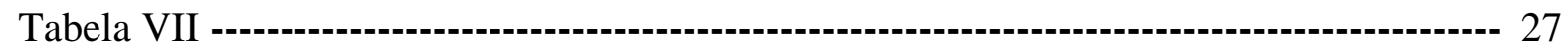

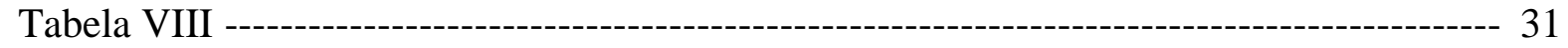

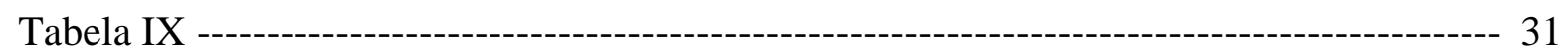

Tabela X -------------------------------------------------------------------------------------------------- 34 


\section{Lista de Abreviações}

BrdU - bromodeoxiuridina

HP - hepatectomia parcial

CEPDBs - células epiteliais pré-ductulares 


\section{Resumo}

O fígado é um órgão importante para se analisar como o animal reage a agressões químicas. Um dos métodos utlizado para estudar a regeneração hepática é a hepatectomia parcial (HP). Assim, nosso objetivo foi verificar a influência da hepatectomia de $30 \%$ e de $70 \%$ sobre a taxa de proliferação das células hepática medida pela incorporação de BrdU na região da incisão e no resto do fígado e a proliferação de ductos biliares e de células epiteliais pré-ductulares biliares (CEPDBs) com o uso de uma combinação de 2 anticorpos específicos para citoqueratinas humanas, AE1/AE3. O pico de proliferação nos animais que sofreram HP de $30 \%$ do parênquima hepático deuse após 1 dia da cirurgia enquanto que os animais que sofreram a HP de $70 \%$ o pico ocorreu no terceiro dia após a cirurgia.O índice de proliferação foi semelhante para a região próxima ou distante do corte. Para ambas as HP não houve diferença na regeneração do tecido retirado próximo ou distante da área de incisão. Nas regiões distantes da HP havia maior número de ductos havendo o pico do número de ductos coincidindo com o pico de proliferação celular de ambas as HP. Depois da HP o número de CEPDBs cresce consideravelmente. Os pico de proliferação também ocorreram no primeiro e terceiro dia para a HP de $30 \%$ e de $70 \%$ respectivamente, sendo mais altos na região distante do corte. Assim, durante a regeneração do fígado de C. gariepinus ocorre hiperplasia compensatória por proliferação de hepatócitos, de ductos biliares e de CEPDBs. A hepatectomia de $30 \%$ gerou uma resposta regenerativa intensa e é menos traumática para o animal, a região distante do corte reage mais intensamente que a região próxima do corte no que se refere aos ductos biliares e as CEPDBs.

Palavras chaves: fígado, regeneração hepática, BrdU, hepatectomia, teleósteos, ductos biliares. 


\begin{abstract}
The liver is an important organ in studies aimed to the verification of animals reactions to chemical injuries. The partial hepatectomy $(\mathrm{PH})$ is one of the methods that are usually employed in hepatic regeneration experiments. Our objectives in this work were to verify the influence of $30 \%$ and $70 \% \mathrm{PH}$ on the hepatic cells proliferation index as it is measured by BrdU nuclear uptake in two regions: close to the hepatic surgery region and in a farther region. The biliary ducts and bile preductular epithelial cells (BPDECs) proliferation was quantified with a combination of two antibodies against the human cytokeratins AE1/AE3. The proliferation index peak in 30\% hepatectomy animals occurred one day after the surgery, but in 70\% hepatectomy animals the peak was only observed after three days from the surgery. Differences between the proliferation index of the close and the far region were not observed and likewise histological differences were absent. In the regions far from the $\mathrm{PH}$ site more biliary ducts were counted than in closer regions, but the peaks were coincident in both regions with the hepatocytes proliferation index. It was also observed that the quantity of BPDECs increased. The peaks occurred in the first and third days for the $30 \%$ and $70 \% \mathrm{PH}$ respectively, and both peaks were higher in the region far from the $\mathrm{PH}$ site. We may conclude that $\mathrm{C}$. gariepinus liver regeneration after $30 \%$ and $70 \%$ PH occurs by means of compensatory hyperplasia by hepatocytes, biliary ducts and BPDECs proliferation. The 30\% $\mathrm{HP}$ stimulated a strong regenerative response and is less traumatic to the animals. The regions far from the $\mathrm{PH}$ site reacts more intensely that the close region concerning the stimulation of biliary ducts and BPDECs proliferation.
\end{abstract}

Key-words: liver, hepatic regeneration, BrDU, hepatectomy, teleost, biliary ducts. 


\section{REGENERAÇÃO HEPÁTICA EM BAGRE AFRICANO (Clarias gariepinus) APÓS HEPATECTOMIA PARCIAL.}

\section{INTRODUÇÃO}

Especialistas em poluição ambiental e em ictiologia estão desenvolvendo estudos para verificar as conseqüências da contaminação dos recursos hídricos por lixo tóxico industrial e doméstico em peixes teleósteos. O fígado é um órgão importante para se avaliar como o animal reage a agressões químicas, sendo que alguns trabalhos estão se concentrando na pesquisa da histopatologia deste órgão. Contudo, outros processos patológicos além dos causados por substâncias tóxicas são encontrados no fígado de teleósteos, o qual é alvo de intensa parasitose em algumas espécies. Também é comum a ocorrencia de neoplasias (Okhiro \& Hinton, 2000) especialmente em peixes que vivem em águas poluídas (Black et al., 1982; Couch \& Harshbager, 1985). 
Os estudos experimentais envolvendo a patologia do fígado de teleósteos têm revelado que, assim como em mamíferos, este órgão possui grande poder regenerativo, e alguns trabalhos sobre regeneração hepática em peixes, ainda que poucos, foram feitos (Kulkarni \& Belsare, 1975, Schultz et al., 1993; Okhiro \& Hinton, 2000). A regeneração do fígado de peixes ocorre a uma velocidade inferior à verificada nos mamíferos (Larsen, 1978; Sanz et al., 1982). O tempo de regeneração em mamíferos depende da espécie e varia conforme os autores. Assim, em ratos, após hepatectomia de $70 \%$ o fígado pode regenerar-se entre sete a dez dias (Wunder, 1976; Larsen, 1978; Sanz, 1982, 1985; Mangnall et al, 2003), sete dias segundo Corbin (2002) e seis a oito dias para Michalopolus (1990). A truta arco-íris regenera o fígado no prazo de 30 dias após HP de 25\% e de 36\%, sendo inclusive incapaz de manter constante no sangue os níveis de proteína, colesterol e de lipídio (Sanz et al, 1985).

Em peixes, os métodos utilizados para estimular a proliferação celular no fígado variam desde a indução de lesões por substância hepatotóxicas à exposição subletal ao calor, ou ao frio (Schultz et al., 1993), passando pela hepatectomia parcial de $70 \%$, 36\%, 25\% e até 3,5\% (Kulkarni \& Belsare, 1975, Sanz et al., 1982; Sanz et al.; 1982, Okhiro \& Hinton, 2000). Todos os métodos de estimulação de regeneração hepática em peixes apresentam vantagens e desvantagens. No caso de exposição a substâncias hepatotóxicas, estas podem alterar o metabolismo hepático e interferir com o processo regenerativo em si mesmo (Schultz et al., 1993). A exposição ao calor ou ao frio intensos podem não ser eficazes naqueles peixes que têm a capacidade de sobreviver em temperaturas extremas. A hepatectomia parcial, um método amplamente utilizado em ratos e camundongos, ainda não foi padronizada em peixes teleósteos. As diferenças entre as porcentagens de 
material hepático retirado podem causar variações nos resultados obtidos. Em ratos e camundongos, o curso da regeneração e a expressão de fatores de crescimento se alteram de acordo com a quantidade de tecido hepático removido (Masson et al., 1999; Dagli, 2001). Em truta, Okihiro \& Hinton (2000) observaram diferenças entre o processo regenerativo no local da hepatectomia e no resto do parênquima hepático após remoção de apenas $0,64 \%$ a $5,58 \%$ do peso total do fígado, em relação a outros trabalhos com retirada de quantidade maior.

Nos peixes, os hepatócitos formam túbulos associados a células biliares. Entre os ductos biliares e os túbulos de hepatócitos existem canais intermediários que são denominados pré-dúctulos biliares. As células que os compõem são chamadas células epiteliais pré-ductulares biliares ou CEPDBs (Hampton et al., 1988; 1989), comparáveis aos canais de Hering, mas que se situam no interior dos túbulos dos hepatócitos. Acredita-se que as CEPDBs sejam as células-fontes de hepatócitos e de células de ductos biliares em fígado de peixes e sejam equivalentes às células ovais de mamíferos e são facilmente diferenciadas das outras células do parênquima por expressarem citoqueratinas AE1/AE3 (Bunton, 1993; Okihiro \& Hinton, 2000).

Saber qual é o momento de maior proliferação celular e quais células proliferam é importante nos experimentos nos quais se pesquisam os efeitos de substâncias sobre células hepáticas em proliferação. É preciso também saber onde colher as amostras para estudo, visto que há a possibilidade de as regiões próximas ou distantes da região de hepatectomia terem reações diferentes (Okihiro \& Hinton, 1996, 2000). Assim, nossos objetivos neste trabalho são verificar a influência da hepatectomia de 1/3 e de 2/3 sobre a índice de proliferação das células hepática medida pela incorporação de BrdU na região 
da incisão e no resto do fígado. Verificaremos ainda se ocorre a proliferação de ductos biliares e de CEPDBs, quando e como ocorre e se há diferenças entre a região próxima e distante da região de hepatectomia com o uso de uma combinação de 2 anticorpos específicos para citoqueratinas humanas, AE1/AE3, que marca estas células em teleósteos quando estão proliferando (Okihiro \& Hinton, 2000). Como modelo biológicos escolhemos o peixe Clarias gariepinus (bagre africano) por ser um animal resistente à manipulação e às condições ambientais. 


\section{MATERIAIS E MÉTODOS}

\subsection{Cirurgia}

Foram usados 30 espécimes machos de bagre africano, com peso entre 200 e 600 gramas fornecidos pelo CEPTA (IBAMA) e aclimatados a $30{ }^{\circ} \mathrm{C}$ por 5 dias. Os animais foram alimentados ad libitum com ração para carpa até o dia anterior à cirurgia. A escolha da ração para esta espécie foi recomendada pelo colaborador deste trabalho, Dr. Paulo S Ceccarelli (IBAMA), sendo fornecida a ração que é usualmente empregada pelo CEPTA para esta espécie.

Para se determinar a quantidade de fígado a ser retirado na hepatectomia de $30 \%$, e $70 \%$ trinta exemplares foram pesados, sacrificados e o fígado foi removido e pesado, sem a vesícula biliar. Constatamos que o índice hepatossomático em C. gariepinus, definido pela fórmula (peso do fígado X 100)/peso corporal varia entre 1,2-1,3, ou seja, o 
peso do fígado representa $1,2 \%$ a 1,3\% do peso corporal para peixes pesando entre $200 \mathrm{~g}$ e 600 g. Esta foi a faixa de peso dos animais usados no experimento. Dessa maneira, calculou-se a porcentagem de tecido hepático que seria retirado a partir do peso total do animal, ou seja, $0,36 \%$ do peso corporal para a hepatectomia de $30 \%$ e $0,84 \%$ do peso corporal para a hepatectomia de 70\%. A anestesia foi realizada por imersão em solução de benzocaína a 80 ppm. A intensidade da anestesia foi avaliada pelo aparecimento seqüencial dos seguintes sinais: incoordenação ao nadar, perda da capacidade de manter a posição normal em relação ao eixo horizontal e vertical, redução dos batimentos operculares e parada dos movimentos operculares. Nesta última fase, os animais foram retirados da solução de anestésico e foram instalados em um aparelho de anestesia que fornecia, por meio de dois tubos inserido na boca do animal, água corrente contendo anestésico e sem anestésico, alternadamente, conforme a necessidade. A anestesia foi controlada pelos batimentos operculares. A solução anestésica era substituído por água doce se os batimentos operculares cessavam por mais de 30 segundos. A assepsia do campo cirúrgico foi feita com solução de álcool iodado. Uma incisão de $5 \mathrm{~cm}$ na linha média, expôs o fígado. Foi seccionada uma porção do lobo esquerdo equivalente a 30\% ou $70 \%$ do peso do fígado. O segmento retirado foi pesado e fixado em líquido fixador metacarn (60\% de metanol, 30\% de clorofórmio e 10\% de ácido acético), por 8 a 12 horas, sendo o controle para aquele animal especificamente.

\subsection{Determinação da concentração ótima de BrdU.}

Devido à inexistência de dados sobre o uso de BrdU nesta espécie, resolvemos testar qual seria a melhor concentração e qual seria o melhor tempo de espera após a 
injeção de BrdU. A BrdU foi dissolvida em PBS em duas concentrações: 20 mg/ml e 30 $\mathrm{mg} / \mathrm{ml}$. Os animais sofreram hepatectomia parcial de 30\%. Assim, 3 grupos de 3 animais receberam intraperitonealmente $20 \mathrm{mg} / \mathrm{kg}$ de BrdU 2 horas antes do sacrifício. Destes, um grupo era o controle sem HP, o segundo grupo sofreu HP 2 dias antes e o segundo sofreu HP 3 dias antes.

Outros 3 grupos de 3 animais passaram pelos mesmos procedimentos, mas receberam $30 \mathrm{mg}$ de BrdU 3 horas antes da retirada do fígado. Um terceiro grupo recebeu 30 mg de BrdU 2 horas antes da amostragem. Os grupos foram denominados como exposto na Tabela $\mathbf{I}$.

Tabela I. Tratamentos com BrdU por grupos de 3 peixes antes da remoção do fígado.

\begin{tabular}{l|l|l|l}
\hline & CONTROLE & HP 2 DIAS & HP 3 DIAS \\
\hline $20 \mathrm{mg} / \mathrm{kg}-2$ horas & G2-2C & G2-2HP2 & G2-2HP3 \\
\hline $30 \mathrm{mg} / \mathrm{kg} 2$ horas & G3-2C & G3-2HP2 & G3-2HP3 \\
\hline $30 \mathrm{mg} / \mathrm{kg}-3$ horas & G3-3C & G3-3HP2 & G3-3HP3 \\
\hline
\end{tabular}

Os fígados foram removidos, pesados, fixados por 8 a 12 horas em líquido fixador metacarn e incluídos em parafina segundo a rotina usual. Para estudo morfológico foram feitas as seguintes colorações: hematoxilina-eosina e picrossírius. 


\subsection{Imuno-histoquímica.}

\subsubsection{BrdU.}

As amostras de fígado foram incluídas em parafina para fins de marcação com anticorpos. A espessura dos cortes foi de 5 micrômetros. Para a evidenciação da BrdU, cortes de 5 micrômetros em lâminas de vidro foram desparafinados. Para evidenciação dos núcleos que incorporaram BrdU, os cortes foram tratados por uma hora com uma solução de $\mathrm{HCl}$ 2N e lavados abundantemente em PBS, tratados com solução de peróxido de hidrogênio a 3\% por 5 minutos para bloqueio da peroxidase endógena e incubados em solução de leite desnatado a 5\% em PBS por 15 minutos a 37 C, para bloqueio de sítios inespecíficos hidrofóbicos. Os cortes foram a seguir incubados com anticorpos monoclonais anti-BrdU (Amersham Life Science, RPN 202) na concentração de 1:600 durante a noite. Após lavagem com PBS as lâminas foram incubadas por 1 hora com anticorpo secundário anti-IgG de camundongo ligado a um polímero contendo peroxidase (Kit Envision -Dako), em seguida, as laminas passaram por uma solução de peroxidase com cromógeno DAB (Kit Envision -Dako) por um período de 10 minutos, sendo lavadas em PBS, desidratadas e montadas.

Para observação destas lâminas foi utilizado um microscópio Axioplan II Zeiss do Laboratório de Biologia Celular do Departamento de Ciências Básicas da Faculdade de Zootecnia e Engenharia de Alimentos da USP. Foram adquiridas imagens dos cortes e contados 1500 núcleos e destes, quantos estavam positivamente marcados com o BrdU para cada peixe, chegando assim ao índice de células na fase S do ciclo celular, ou índice de proliferação nuclear que foi expresso em porcentagem de núcleos marcados por número total ou núcleos no campo histológico. 


\subsubsection{Citoqueratina.}

As amostras de fígado foram incluídas em parafina, para a evidenciação das células que expressavam citoqueratina. Os cortes em lâminas de vidro com de 5 micrômetros foram desparafinados, lavados abundantemente em PBS, tratados com solução de peróxido de hidrogênio a 3\% por 5 minutos para bloqueio da peroxidase endógena e incubados por 30 minutos em solução de leite desnatado a 5\% em PBS a $37^{\circ} \mathrm{C}$ para bloqueio de sítios inespecíficos. Os cortes foram a seguir lavados com PBS, incubados com anticorpo monoclonal de camundongo anti-citoqueratina humana, AE1/AE3 (Dako- AE1/AE3) na concentração de 1:100 durante a noite. Após lavagem com PBS as lâminas foram incubadas por 1 hora com anticorpo secundário anticamundongo ligado a um polímero com peroxidase (Kit Envision - Dako), após lavagem em PBS, as lâminas passaram por uma solução de cromógeno DAB (Kit Envision -Dako) por um período de 7 a 10 minutos, a seguir, as lâminas foram lavadas em PBS e foi feita uma coloração de fundo com hematoxilina para evidenciar as células marcadas.

A contagem das células positivas à citoqueratina AE1/AE3 foi feita pela quantificaçäo das células, utilizando-se 10 campos de $72.840 \mu \mathrm{m} 2$ por animal, com objetiva de 20x, obtendo assim uma média de células por campo. Utilizaram-se apenas campos que não incluiam ductos biliares e vasos sanguíneos de grande porte. 


\subsubsection{Ductos Biliares.}

Para marcar e evidenciar os ducto biliares foi utilizado o mesmo protocolo usado para a citoqueratina, visto que o epitélio cúbico dos ductos biliares reage intensamente com os anticorpos anti-citoqueratinas AE1/AE3, assim como as células epiteliais préductulares biliares.

Para a avaliaçäo do número de ductos biliares, foi realizada uma contagem de 5 campos de $72.840 \mu \mathrm{m} 2$ (com a objetiva de 20x) por animal, obtendo-se uma média por prazo nas regiões próxima e distante da HP, nas duas HP (30 e 70\%). 


\section{RESULTADOS}

\subsection{Anatomia}

O fígado do C. gariepinus é encontrado logo sob a camada muscular da cavidade abdominal, sendo facilmente exposto. Está dividido em dois lobos unidos por uma ponte espessa, o lobo direito e o lobo esquerdo que se estendem lateralmente por meio de uma projeção alongada e estreita, a qual se insere na parede abdominal lateral, onde o lobo volta a dilatar-se, formando um segmento arredondado intramural (Figura 1). A vesícula biliar localiza-se na porção caudal dorsal do lobo direito. As HP de 30\% foram realizadas no lobo esquerdo, retirando-se a porção inferior deste lobo, enquanto que na HP de 70\%, retirou-se a totalidade do lobo esquerdo e parte do direito, tomando-se cuidado para não afetar a vesícula biliar.

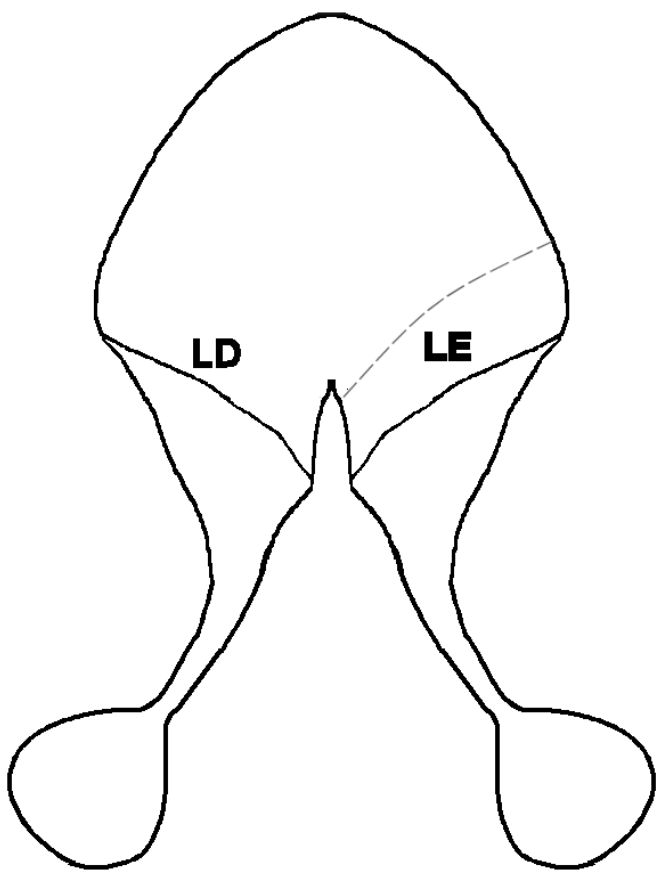

Figura 1. Representação esquemática do fígado de Clarias gariepinus, vista ventral. A porção superior da figura é a extremidade cranial. O fígado é formado por dois lobos idênticos, o lobo direito (LD) e o lobo esquerdo (LE). Na hepatectomia de 30\% é retirada parte do lobo esquerdo (aproximadamente na linha pontilhada). 


\subsection{Histomorfologia}

O fígado do C. gariepinus é revestido pelo epitélio pavimentoso simples (mesotélio) apoiado sobre uma lâmina de tecido conjuntivo denso, formando uma cápsula serosa. No interior do parênquima hepático, aglomerados maiores de fibras colágenas apenas são encontrados ao redor de vasos maiores ou ductos biliares, não se percebe tecido conjuntivo interlobular delimitando os lóbulos como nos mamíferos. Os ramos da veia porta, da artéria hepática e do ducto biliar raramente são encontradas formando um conjunto; assim não há uma estrutura comparável ao espaço porta dos mamíferos. Com a ausência de um espaço porta bem definido, tivemos de adotar outros critérios já sugeridos na literatura, para diferenciar a veia central, ou o ramo da veia hepática, e os ramos da veia porta. Os ramos da veia porta geralmente são maiores, apresentam sangue em sua luz e possuem mais tecido conjuntivo em sua camada adventícia, sendo este o seu aspecto mais típico. A veia porta parece estar no centro das irradiações dos cordões de hepatócitos, ao contrário do que ocorre em mamíferos na qual essa irradiação acaba na veia central ou como chamaremos, veia hepática (figura 2a e 2c).

Os hepatócitos formam cordões delimitados por vasos sinusóides que irradiam da veia porta. Entre os cordões, ocasionalmente, pequenos ductos biliares podem ser observados (figura 2b). Estes não são frequentes no parênquima hepático. Os cordões de hepatócitos e os vasos sinusóides que se dirigem para várias veias hepáticas dispersas pelo parênquima (figura 2d).

Os hepatócitos são células grandes, com núcleo grande e arredondado apresentando um nucléolo evidente. O citoplasma apresenta-se vacuolizado e ligeiramente basófilo, os vacúolos provavelmente representam gotículas de lipídios ou 
material energético de reserva. Entre os hepatócitos podem ser observadas núcleos menores e alongados que podem formar um canal arredondado de parede delgada. Os ductos biliares são formados por epitélio cúbico, circundados por tecido conjuntivo; melanomacrófagos podem ser encontrados próximos a estas estruturas (figura 3f).
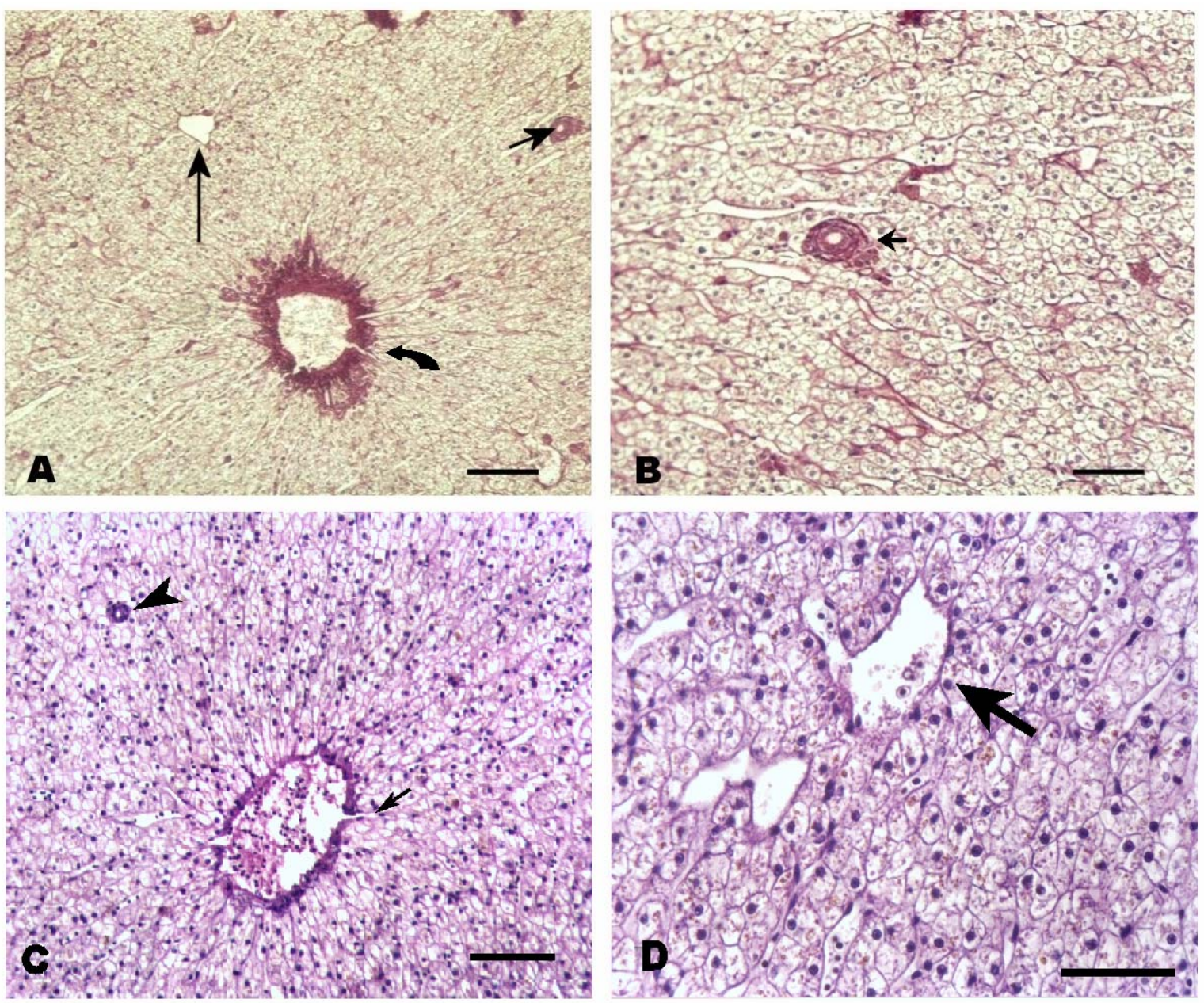

Figura 2. Fígado de animal controle. a) Neste campo podem ser observados um ramo da veia porta, contendo abundadente colágeno em sua parede com as placas de hepatócitos irradiando dali para o interior do parênquima. No mesmo campo, nota-se um ramo da veia hepática (seta longa) e um pequeno ducto biliar (seta curta). Barra $=100 \mu$. b) Os hepatócitos formam placas delimitadas por vasos sinusóides. No centro da imagem, está presente um ducto biliar (seta), caracteristicamente cercado por tecido conjuntivo. Barra $=40 \mu$. Ambas as preparações foram coradas pelo Picrossírios-Hematoxilina. c) Veia porta com células sangüíneas em seu interior. Notar um ducto biliar (ponta de seta) e de um sinusóide irradiando-se a partir da veia central (seta). A veia porta no C. gariepinus parece estar no centro das irradiações, ao contrário dos mamíferos na qual o centro dessas irradiações é ocupada pela veia central. Barra $=50 \mu$. d) Veia hepática com sua aparência característica sem muito colágeno (seta). Os vasos sinusóides confluem para a veia hepáticas. Nos animais controles, os hepatócitos apresentam o citoplasma claro e vacuolizado. Barra mede $=30 \mu$. Ambas as preparações foram coradas pelo método de hematoxilina-eosina. 


\section{$3.3 \quad$ Hepatectomia de $\mathbf{3 0} \%$}

\subsubsection{Modificações histológicas}

O aspecto histológico do tecido hepático colhido perto ou distante do local da incisão não apresentou diferenças estruturais importantes, as principais diferenças estruturais observadas foram relativas à quantidade de tecido hepático retirado, isto é, entre a HP de $30 \%$ e de $70 \%$.

Após um dia da HP de $30 \%$ os sinusóides estavam levemente dilatados e os cordões de hepatócitos ligeiramente desorganizados, sendo a aparência dos hepatócitos igual à do controle (figura 3b). Com 2 dias os vasos sinusóides do tecido próximo à ferida se apresentam dilatados, congestos e irregulares. O número de ductos biliares aumenta. A disposição cordonal ou em placas dos hepatócitos fica menos evidente. Os hepatócitos são menores, com o citoplasma basófilo. Nas amostras de fígado tomadas longe do local da ablação, os capilares sinusóides também apresentam-se mais dilatados e congestos (figura 3d). A dilatação dos capilares e a congestão diminuem após 3 dias. As células retomam o tamanho original (figura 3f).

Com quatro dias continua a regressão da desorganização dos hepatócitos e o arranjo microscópico estrutural volta a assemelhar-se ao do controle. No último prazo os hepatócitos estão organizados em cordões evidentes ao longo de sinusóides, mas ainda näo apresentam as dimensões originais. Os trajetos dos sinusóides e dos cordões ainda são irregulares (figura 3h). 

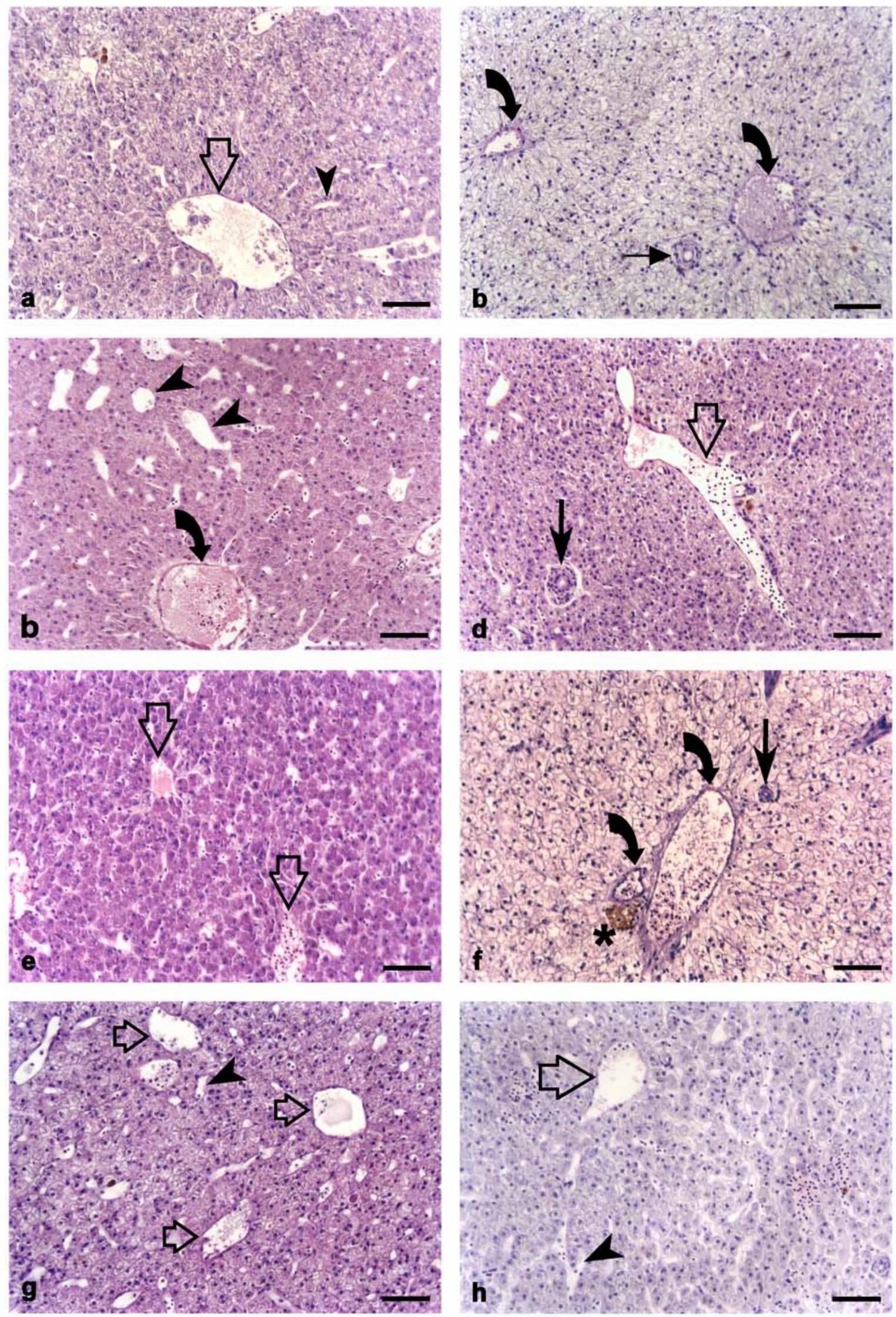
Figura 3. O cortes histológicos mostram aspectos do fígado após HP de 30\% e 70\% nos prazos de 1,2,3 e 5 dias. As lâminas foram coradas pela hematoxilina-eosina. A coluna de fotomicrografias da esquerda mostra os resultados para a HP de 70\%, a da direita mostra os resultados para a HP de 70. Coloração: hematoxilina-Eosina.

a) HP de $70 \%$ após um dia. Os sinusóides começam a apresentar dilatação (ponta de seta) e trajeto tortuoso, as células são menores e o citoplasma torna-se basófilo. Uma veia central está indicada (seta vazada). Barra $=50$ $\mu$.

c) HP de $70 \%$ com 2 dias. Aumento da dilatação e desarranjo dos sinusóides (ponta de seta) cuja luz tem tamanho variável. Eles não parecem mais irradiar da veia porta (seta curva). Barra $=50 \mu$.

e) $\mathrm{HP}$ de $70 \%$ com 3 dias. Nesse prazo o parênquima perde a arquitetura característica, deixando os hepatócitos de formar cordões ou placas regulares. As células ficam bastante arredondadas e os sinusóides tem orientação irregular. A quantidade de veias hepáticas (setas vazadas) aumenta. Barra $=50 \mu$.

g) HP de $70 \%$ com 5 dias. Os sinusóides (ponta de seta) e os cordões de hepatócitos ainda não se apresentam como no controle, o trajeto dos sinusóides é ainda irregular e ocorre proliferação de ramos das veias hepáticas (setas vazadas). Barra $=50 \mu$. b) HP de 30\% após 1 dia. Os sinusóides se apresentam levemente dilatados e os cordões de hepatócitos levemente desorganizados, sendo o tamanho igual a do controle. Observam-se veias portas (setas curvas) e um ramo da artéria hepática (seta). Notar como os cordões de hepatócitos se irradiam a partir das veias portas, assemelhando-se a lóbulos. Barra $=50 \mu$

d) HP de 30\% com 2 dias. Os vasos sinusóides próximos à lesão se apresentam dilatados, congestos e irregulares, as células são pequenas e basófilas. Uma veia central (seta vazada) e um ducto biliar (seta) estão apontados Barra = $50 \mu$

f) HP de $30 \%$ com 3 dias. A dilatação e congestão dos capilares diminuem e as células retomam o tamanho original. No campo podem ser observados duas veias portas (setas curvas) um ducto biliar (seta) e um melanomacrófago (*). Barra $=50 \mu$.

h) HP de $30 \%$ com 5 dias. Assim como para a HP de 70\% os sinusóides (ponta de seta) e os cordões de hepatócitos ainda não apresentam as dimensões originais, os trajetos destes ainda são muito sinuosos e seu aspecto é mais homogêneo. Uma veia central está presente no campo (seta vazada). Barra $=50 \mu$. 


\subsection{2 Índice de proliferação celular medido pela BrdU}

O pico do índice de proliferação ocorreu no primeiro dia após a HP nos animais que sofreram ablação de $30 \%$ do fígado. O valor médio do índice de proliferação neste prazo (porcentagem de células positivas à BrdU) foi de 28,7\% e de 28,4\% respectivamente para a região próxima e para a distante da ablação, tendo a análise estatística demonstrado que as médias eram iguais (figuras 4 e 5, Tabelas II, III). A partir do segundo dia depois da HP o índice de proliferação celular declina, como pode ser observado na Tabela III. A comparação estatística das médias revelou que não há diferenças entre os índices de proliferação celular de regiões próximas ou distantes do corte neste tipo de hepatectomia. Com cinco dias (último prazo) os índices são de 17,3\% para perto e 16,3\% para longe, porém esses valores ainda são maiores que os do controle $(7,96 \% \pm 1,42)$. As figuras $5 \mathbf{a}$ e $\mathbf{5 b}$ mostram respectivamente a distribuição dos núcleos nos fígados de animais controles e no dos animais com um dia de HP de 30\%, quando ocorreu o pico de proliferação celular. 
Tabela II. Índices de proliferação celular de fígados de C. gariepinus submetidos à hepatectomia parcial de $30 \%$ e de $70 \%$, expressados pela porcentagem de núcleos positivos à BrdU entre 1500 núcleos de regiões hepaticas próximas ao local da operação $(P)$ e distantes do local da operação (D) entre um a cinco dias depois da cirurgia.

Dias após a hepatectomia

\begin{tabular}{|c|c|c|c|c|c|c|c|}
\hline \multirow[b]{2}{*}{$\begin{array}{c}\text { Tipo } \\
\text { de } \\
\text { HP } \\
\end{array}$} & \multirow[b]{2}{*}{ Local } & \\
\hline & & 0 & 1 & 2 & 3 & 4 & 5 \\
\hline \multirow{2}{*}{$30 \%$} & $P$ & - & $\begin{array}{c}28,7 \pm 4,2 \\
(81)\end{array}$ & $\begin{array}{c}23,0 \pm 7,8 \\
(81)\end{array}$ & $\begin{array}{c}19,0 \pm 2,2 \\
(53)\end{array}$ & $\begin{array}{c}20,2 \pm 4,4 \\
(68)\end{array}$ & $\begin{array}{c}17,3 \pm 3,0 \\
(58)\end{array}$ \\
\hline & D & - & $\begin{array}{c}28,0 \pm 5,7 \\
(78)\end{array}$ & $\begin{array}{c}23,0 \pm 7,3 \\
(61)\end{array}$ & $\begin{array}{c}20,6 \pm 4,3 \\
(50)\end{array}$ & $\begin{array}{c}21,9 \pm 4,1 \\
(58)\end{array}$ & $\begin{array}{c}16,3 \pm 2,5 \\
(69)\end{array}$ \\
\hline \multirow{2}{*}{$70 \%$} & $\mathbf{P}$ & - & $\begin{array}{c}18,1 \pm 2,6 \\
(46)\end{array}$ & $\begin{array}{c}20,8 \pm 1,3 \\
(37) \\
\end{array}$ & $\begin{array}{c}26,6 \pm 3,8 \\
(45)\end{array}$ & $\begin{array}{c}20,7 \pm 4,9 \\
(50)\end{array}$ & $\begin{array}{c}18,5 \pm 7,7 \\
(48)\end{array}$ \\
\hline & D & - & $\begin{array}{c}20,5 \pm 2,5 \\
(46)\end{array}$ & $\begin{array}{c}21,2 \pm 3,2 \\
(66)\end{array}$ & $\begin{array}{c}26,7 \pm 3,8 \\
(45)\end{array}$ & $\begin{array}{c}21,6 \pm 6,6 \\
(50)\end{array}$ & $\begin{array}{c}20,2 \pm 4,4 \\
(52)\end{array}$ \\
\hline C & - & $\begin{array}{c}8 \pm 1,4 \\
(33)\end{array}$ & - & - & - & - & - \\
\hline
\end{tabular}

Os números representam as médias seguidas do desvio padrão, os valores entre parênteses representam o número de observações que compõem a média $(n)$. $P=$ perto; $D=\operatorname{distante;~} C=$ animais controle.

Tabela III. Comparação do índice de proliferação de regiões hepaticas próximas ao local da ablação (P) e distantes do local da ablação (D) entre um a cinco dias depois hepatectomia parcial de $30 \%$ em C. gariepinus, obtido pela porcentagem de núcleos positivos à BrdU em 1500 núcleos.

\begin{tabular}{|c|c|c|c|c|c|c|c|}
\hline \multirow[b]{2}{*}{$\begin{array}{c}\text { Tipo } \\
\text { de } \\
\text { HP }\end{array}$} & \multirow[b]{2}{*}{ Local } & \multicolumn{6}{|c|}{ Dias após a hepatectomia } \\
\hline & & 0 & 1 & 2 & 3 & 4 & 5 \\
\hline \multirow{2}{*}{$30 \%$} & $\mathbf{P}$ & - & $\begin{array}{c}28,7 \pm 4,2 \\
(81) a A\end{array}$ & $\begin{array}{c}23,0 \pm 7,8 \\
(81) b B\end{array}$ & $\begin{array}{c}19,0 \pm 2,2 \\
(53) c C\end{array}$ & $\begin{array}{c}20,2 \pm 4,4 \\
(68) \mathrm{d} C\end{array}$ & $\begin{array}{c}17,3 \pm 3,0 \\
\text { (58)eD }\end{array}$ \\
\hline & D & - & $\begin{array}{c}28,0 \pm 5,7 \\
(78) a A\end{array}$ & $\begin{array}{c}23,0 \pm 7,3 \\
(61) b B\end{array}$ & $\begin{array}{c}20,6 \pm 4,3 \\
(50) \text { cB }\end{array}$ & $\begin{array}{c}21,9 \pm 4,1 \\
(58) \mathrm{dB}\end{array}$ & $\begin{array}{c}16,3 \pm 2,5 \\
\text { (69)ec }\end{array}$ \\
\hline C & - & $\begin{array}{c}8 \pm 1,4 \\
(33)\end{array}$ & - & - & - & - & - \\
\hline
\end{tabular}

Os números representam as médias seguidas do desvio padrão; os valores entre parênteses são o número de observações que compõem a média $(\mathrm{n})$. As médias foram comparadas pelo método de comparações múltiplas de médias aos pares usando-se o teste de Tukey com alfa $<0,05$. As letras minúsculas comparam as médias nas colunas, as médias com letras iguais não são estatisticamente diferentes. As letras maiúsculas comparam as médias nas linhas, as médias com letras iguais não são estatisticamente diferentes. $P=$ perto; $D=$ distante; $C=$ animais controle. 
Índice de proliferação de hepatócitos em animais submetidos à hepatectomia de $30 \%$



$\square$ Distante

Dróxima

Controle

Figura 4. Gráfico comparando o índice de proliferação celular das regiões distante e próxima da zona de hepatectomia de 30\%. As respostas proliferativas foram semelhantes em ambas as zonas, sendo que o pico de proliferação ocorreu logo no primeiro dia depois da hepatectomia, com redução progressiva até o quinto dia. 


\subsection{Hepatectomia de $\mathbf{7 0} \%$.}

\subsubsection{Modificações histológicas}

Na HP de 70\%, no primeiro dia, os sinusóides e os cordões começam a apresentar-se dilatados e com trajeto tortuoso. As células tornam-se menores e o citoplasma fica mais basófilo (figura 3a). No segundo dia há o aumento da dilatação e do dessarranjo dos sinusóides, cuja luz tem tamanho variável, mas ainda é possivel observar os hepatócitos formando cordões (figura 3c). No terceiro dia, os hepatócitos deixam de formar cordões regulares, tornam-se pequenos e arredondados, os sinusóides formam lacunas repletas de sangue e a estrutura histológica do fígado se altera (figura 3e). No quarto dia os cordões e a vascularização dos sinusóides surgem mais organizados. Com cinco dias a reorganização dos hepatócitos em cordões é mais evidente, acompanhando sinusóides de trajeto mais definido, embora ainda irregular. Nota-se também a proliferação de ramos das veias hepáticas (figura 3g).

\subsection{2 Índice de proliferação celular medido pela BrdU}

O pico do índice de proliferação ocorreu no terceiro dia após a HP nos animais que sofreram ablação de 70\% do fígado. O valor médio do índice de proliferação neste prazo foi de $26,6 \%$ e de $26,7 \%$ respectivamente para a região próxima e para a região distante da ablação, tendo a análise estatística demonstrado que as médias eram iguais (figuras 5c, 6 e Tabelas II, IV). Assim como na HP de 30\%, os valores médios do índice de proliferação celular das regiões próxima e distante não são estatisticamente diferentes. As figuras 5a e 5c mostram respectivamente a distribuição dos núcleos nos fígados de animais controles e no dos animais com três dias de HP de 70\%. 


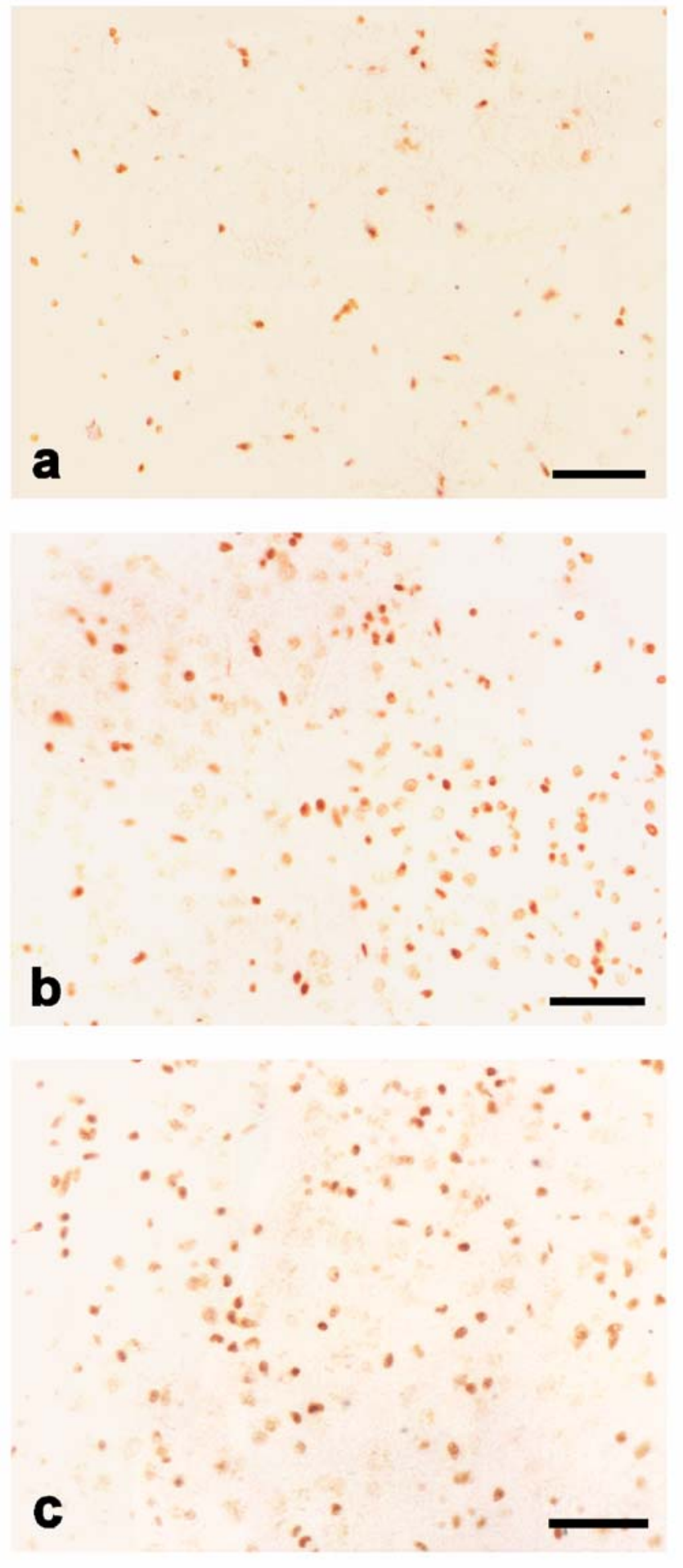

Figura 5. Fotomicrografias mostrando a incorporação de BrdU pelos núcleos dos hepatócitos nos animais controles, durante o pico de proliferação celular pós HP de 30\% e 70\%. Técnica imunohistoquímica com revelação pelo método de peroxidase-DAB. Barra mede $=30 \mu \mathrm{em}$ todas as imagens. a) Núcleos de hepatócitos de animal controle. b) Animal submetido à HP de 30\%, primeiro dia, onde ocorreu o pico de incorporação da Brdu. Notar o aumento do número de núcleos marcados em relação ao animal controle. c) Animal submetido à HP de 70\%, terceiro dia, onde ocorreu o pico de incorporação da Brdu. Como na imagem anterior, notar aumento do número de núcleos marcados em relação ao animal controle. 
Tabela IV. Comparação do índice de proliferação celular de regiões hepaticas próximas ao local da operação $(P)$ e distantes do local da operação (D) entre um a cinco dias depois hepatectomia parcial de $70 \%$ em C. gariepinus, obtido pela porcentagem de núcleos positivos à BrdU em 1500 núcleos.

\begin{tabular}{|c|c|c|c|c|c|c|c|}
\hline \multirow[b]{2}{*}{$\begin{array}{c}\text { Tipo } \\
\text { de } \\
\text { HP }\end{array}$} & \multirow[b]{2}{*}{ Local } & \multicolumn{6}{|c|}{ Dias após a hepatectomia } \\
\hline & & 0 & 1 & 2 & 3 & 4 & 5 \\
\hline \multirow{2}{*}{$70 \%$} & $\mathbf{P}$ & - & $\begin{array}{c}18,1 \pm 2,6 \\
(46) \mathrm{aA}\end{array}$ & $\begin{array}{c}20,8 \pm 1,3 \\
(37) \mathrm{bA}\end{array}$ & $\begin{array}{c}26,6 \pm 3,8 \\
(45) \mathrm{cB}\end{array}$ & $\begin{array}{c}20,7 \pm 4,9 \\
(50) \mathrm{dC}\end{array}$ & $\begin{array}{c}18,5 \pm 7,7 \\
(48) \mathrm{eC}\end{array}$ \\
\hline & D & - & $\begin{array}{c}20,5 \pm 2,5 \\
(46) a A\end{array}$ & $\begin{array}{c}21,2 \pm 3,2 \\
(66) b A\end{array}$ & $\begin{array}{c}26,7 \pm 3,8 \\
(45) \mathrm{cB}\end{array}$ & $\begin{array}{c}21,6 \pm 6,6 \\
(50) \mathrm{d} C\end{array}$ & $\begin{array}{c}20,2 \pm 4,4 \\
(52) \text { ec }\end{array}$ \\
\hline C & - & $\begin{array}{c}8 \pm 1,4 \\
(33)\end{array}$ & - & - & - & - & - \\
\hline
\end{tabular}

Os números representam as médias seguidas do desvio padrão, os valores entre parênteses representam o número de observações que compõem a média (n). As médias foram comparadas pelo método de comparações múltiplas de médias aos pares usando-se o teste de Tukey com alfa $<0,05$. As letras minúsculas comparam as médias nas colunas, as médias com letras iguais não são estatisticamente diferentes. As letras maiúsculas comparam as médias nas linhas, as médias com letras iguais não são estatisticamente diferentes. $P=$ perto; $D=$ distante; $\mathrm{C}=$ animais controle. 
Índice de proliferação de hepatócitos em animais submetidos à hepatectomia de $70 \%$

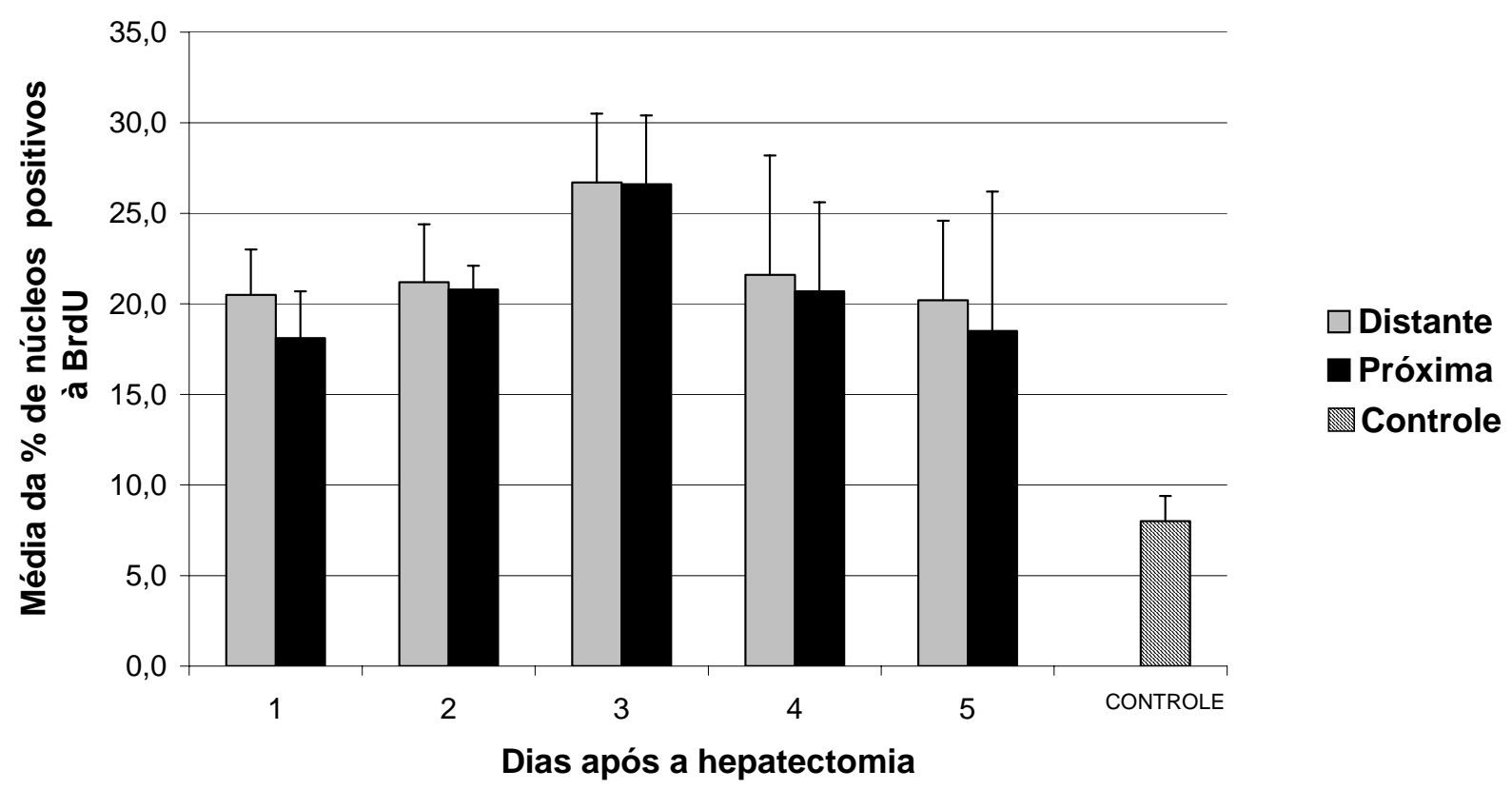

Figura 6. Gráfico comparando a resposta proliferativa das regiões distante e próxima da zona de hepatectomia de $70 \%$. As respostas proliferativas foram semelhantes em ambas as zonas, sendo que o pico de proliferação ocorreu logo no primeiro dia depois da hepatectomia, com redução progressiva até o quinto dia. 


\subsection{Ductos Biliares.}

Os ductos biliares são revestidos por um epitélio cúbico simples e circundados por fibroblastos formando uma parede espessa. Seu tamanho varia, mas em geral são pequenos, sendo que a maioria tem entre 20 a 40 micrômetros de diâmetro. Geralmente encontram-se isolados no parênquima hepático, distantes de outras estruturas como veias ou artérias, diversamente do observado em mamíferos. Contudo, às vezes, podem ser observados próximos à veias hepáticas (figura 3d e 7a).

A média de ductos biliares em 15 campos microscópicos em peixes controles foi de 7,5 ductos e todos revelaram expressão imuno-histoquímica de citoqueratinas AE1/AE3 (Tabela V, VI). Em ambos os tipos de HP (30\% ou 70\%) foi observado um aumento da quantidade de ductos biliares por campo em relação ao controle, contudo o aumento foi maior nas regiöes distantes do corte. Embora o número de ductos por campo microscópico fosse maior nos animais que sofreram hepatectomia, estes eram pequenos e a expressão imuno-histoquímica de citoqueratinas AE1/AE3 na células epiteliais foi mais intensa que a observada nos animais controles (figura 7a, figura 7c).

Nas regiões distantes do corte, tanto na HP de 30\% como na de $70 \%$, o pico da quantidade de ductos por campo coincidiu com o pico do índice de proliferação celular medido pela incorporação de BrdU, isto é na HP de 30\% o pico ocorreu no primeiro dia (média de 18,5 ductos por campo) e na HP de 70\% o pico (média de 18,5 ductos por campo) foi observado no terceiro dia (Tabela V, VI e figura 8). 
Os ductos da região próxima ao corte apresentaram dois picos de proliferação tanto na HP de 30\% como na HP de 70\% (Tabela VII e figura 9). Um dos picos ocorre no primeiro dia (média de 12,5 para HP de 30\% e de 13,7 para a HP de 70\%) e o outro pico ocorre no quinto dia (média de 10,7 para HP de 30\% e de 18,9 para a HP de 70\%).
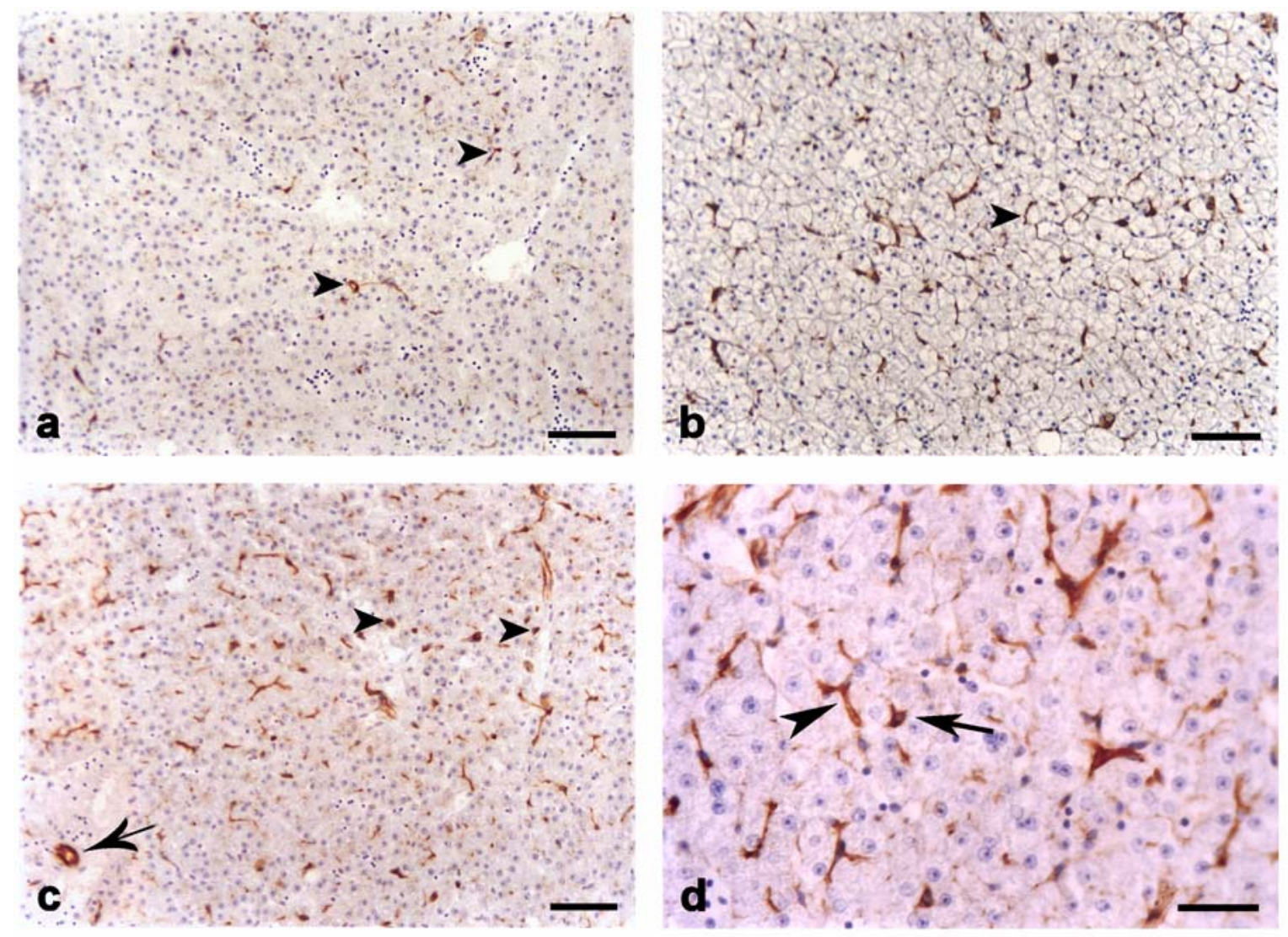

Figura 7. Fotomicrografias mostrando as células expressando as citoqueratinas AE1/AE3 reveladas pela técnica imuno-histoquímica com o método de peroxidase-DAB e com hematoxilina como coloração de fundo. As setas apontam ductos biliares. a) Animal controle. Os ductos biliares normalmente se encontram isolados no parênquima hepático, aqui ele aparece próxima à uma veia hepática. Barra $=100 \mu$. b) Aparência característica de um ducto biliar em um peixe controle. $\mathrm{O}$ epitélio dos ductos biliares reage fortemente com os anticorpos anti-citoqueratinas, permitindo sua fácil diferenciação. Barra $=50 \mu$. c) HP de 30\%, primeiro dia, região distante da incisão. Esta imagem ilustra o momento do pico na HP de 30\%, sendo possível observar cinco ductos no campo. Barra $=100 \mu$. 
Tabela V. Comparação da quantidade de ductos biliares por campo próximos ao local da operação $(P)$ e distantes do local da operação (D) entre um a cinco dias depois hepatectomia parcial de $30 \%$ e de $70 \%$ em C. gariepinus.

Dias após a hepatectomia

\begin{tabular}{cccccccc}
$\begin{array}{c}\text { Tipo } \\
\text { de } \\
\text { HP }\end{array}$ & Local & $\mathbf{0}$ & $\mathbf{1}$ & $\mathbf{2}$ & $\mathbf{3}$ & $\mathbf{4}$ & $\mathbf{5}$ \\
\cline { 2 - 8 } & $\mathbf{P}$ & - & $\begin{array}{c}12,5 \pm 1,6 \\
(15)\end{array}$ & $\begin{array}{c}10,3 \pm 1,4 \\
(15)\end{array}$ & $\begin{array}{c}8,1 \pm 2 \\
(15)\end{array}$ & $\begin{array}{c}8,5 \pm 1,5 \\
(15)\end{array}$ & $\begin{array}{c}10,7 \pm 1,7 \\
(15)\end{array}$ \\
\cline { 2 - 7 } $\mathbf{3 0 \%}$ & $\mathbf{D}$ & - & $18,5 \pm 1,0$ & $15,5 \pm 1,1$ & $15,1 \pm 0,8$ & $13,2 \pm 1,6$ & $14,3 \pm 1,9$ \\
& & & $(15)$ & $(15)$ & $(15)$ & $(15)$ & $(15)$ \\
\hline & $\mathbf{P}$ & - & $13,7 \pm 2,9$ & $12,3 \pm 1,2$ & $13,5 \pm 2,6$ & $9,1 \pm 0.9$ & $18,9 \pm 0,7$ \\
$\mathbf{7 0 \%}$ & & & $(15)$ & $(15)$ & $(15)$ & $(15)$ & $(15)$ \\
\cline { 2 - 8 } & $\mathbf{D}$ & - & $16,5 \pm 3,6$ & $18,0 \pm 1,3$ & $18,5 \pm 1,2$ & $12,8 \pm 1,4$ & $11,7 \pm 1,2$ \\
& & & $(15)$ & $(15)$ & $(15)$ & $(15)$ & $(15)$ \\
\hline $\mathbf{C}$ & - & $7,5 \pm 1,5$ & - & - & - & - & - \\
\hline
\end{tabular}

Os números representam as médias seguidas do desvio padrão, os valores entre parênteses representam o número de observações (n).

Tabela VI. Comparação da quantidade de ductos biliares por campo próximos ao local da operação (P) e distantes do local da operação (D) entre um a cinco dias depois hepatectomia parcial de $30 \%$ em C. gariepinus.

\begin{tabular}{|c|c|c|c|c|c|c|c|}
\hline \multirow[b]{2}{*}{$\begin{array}{c}\text { Tipo } \\
\text { de } \\
\text { HP }\end{array}$} & \multirow[b]{2}{*}{ Local } & \multicolumn{5}{|c|}{ Dias após a hepatectomia } & \multirow[b]{2}{*}{5} \\
\hline & & 0 & 1 & 2 & 3 & 4 & \\
\hline \multirow{2}{*}{$30 \%$} & $\mathbf{P}$ & - & $\begin{array}{c}12,5 \pm 1,6 \\
(15) \mathrm{aA}\end{array}$ & $\begin{array}{c}10,3 \pm 1,4 \\
(15) a B\end{array}$ & $\begin{array}{c}8,1 \pm 2 \\
(15) \mathrm{aC}\end{array}$ & $\begin{array}{c}8,5 \pm 1,5 \\
(15) \mathrm{aC}\end{array}$ & $\begin{array}{c}10,7 \pm 1,7 \\
(15) \mathrm{aD}\end{array}$ \\
\hline & D & - & $\begin{array}{c}18,5 \pm 1,0 \\
(15) b A\end{array}$ & $\begin{array}{c}15,5 \pm 1,1 \\
(15) b B\end{array}$ & $\begin{array}{c}15,1 \pm 0,8 \\
(15) b B\end{array}$ & $\begin{array}{c}13,2 \pm 1,6 \\
(15) b c\end{array}$ & $\begin{array}{c}14,3 \pm 1,9 \\
(15) b c\end{array}$ \\
\hline C & - & $\begin{array}{c}7,5 \pm 1,5 \\
(15)\end{array}$ & - & - & - & - & - \\
\hline
\end{tabular}

Os números representam as médias seguidas do desvio padrão, os valores entre parênteses representam o número de observações $(n)$. As médias foram comparadas pelo método de comparações múltiplas de médias aos pares usando-se o teste de Tukey com alfa $<0,05$. As letras minúsculas comparam as médias nas colunas, as médias com letras iguais não são estatisticamente diferentes. As letras maiúsculas comparam as médias nas linhas, as médias com letras iguais não são estatisticamente diferentes. $P=$ perto; $D=$ distante; $C=$ animais controle. 


\section{Quantidade de ductos biliares por campo em animais submetidos à hepatectomia de $30 \%$}

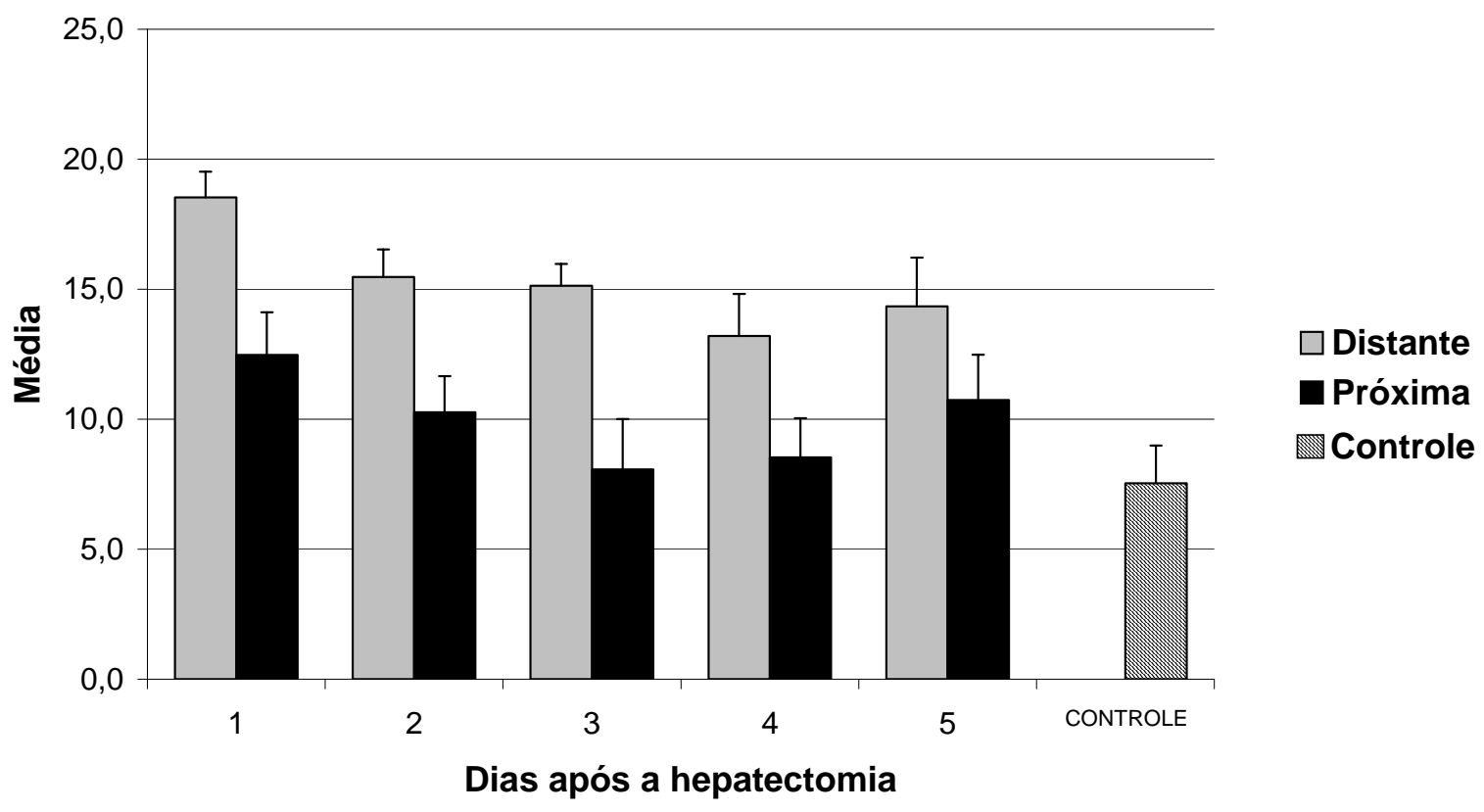

Figura 8. Gráfico comparando as médias do número de ductos biliares das regiöes distante e próxima da hepatectomia de $30 \%$. A quantidade de ductos biliares é superior nas regiões distantes ao corte em todos os tempos.

Tabela VII. Comparação da quantidade de ductos biliares por campo próximos ao local da operação $(P)$ e distantes do local da operação $(D)$ entre um a cinco dias depois hepatectomia parcial de $70 \%$ em C. gariepinus.

\begin{tabular}{|c|c|c|c|c|c|c|c|}
\hline \multirow[b]{2}{*}{$\begin{array}{l}\text { Tipo } \\
\text { de } \\
\text { HP }\end{array}$} & \multirow{2}{*}{ Local } & \multicolumn{5}{|c|}{ Dias após a hepatectomia } & \multirow[b]{2}{*}{5} \\
\hline & & 0 & 1 & 2 & 3 & 4 & \\
\hline \multirow{2}{*}{$70 \%$} & $\mathbf{P}$ & - & $\begin{array}{c}13,7 \pm 2,9 \\
(15) a A\end{array}$ & $\begin{array}{c}12,3 \pm 1,2 \\
(15) a A\end{array}$ & $\begin{array}{c}13,5 \pm 2,6 \\
(15) a A\end{array}$ & $\begin{array}{l}9,1 \pm 0.9 \\
(15) \mathrm{aB}\end{array}$ & $\begin{array}{c}18,9 \pm 0,7 \\
(15) a C\end{array}$ \\
\hline & D & - & $\begin{array}{c}16,5 \pm 3,6 \\
(15) \mathrm{bA}\end{array}$ & $\begin{array}{c}18,0 \pm 1,3 \\
(15) \mathrm{bA}\end{array}$ & $\begin{array}{c}18,5 \pm 1,2 \\
(15) b A\end{array}$ & $\begin{array}{c}12,8 \pm 1,4 \\
(15) b B\end{array}$ & $\begin{array}{c}11,7 \pm 1,2 \\
(15) b c\end{array}$ \\
\hline C & - & $\begin{array}{c}7,5 \pm 1,5 \\
(15)\end{array}$ & - & - & - & - & - \\
\hline
\end{tabular}

\footnotetext{
Os números representam as médias seguidas do desvio padrão, os valores entre parênteses representam o número de observações (n). As médias foram comparadas pelo método de comparações múltiplas de médias aos pares usando-se o teste de Tukey com alfa <0,05. As letras minúsculas comparam as médias nas colunas, as médias com letras iguais não são estatisticamente diferentes. As letras maiúsculas comparam as médias nas linhas, as médias com letras iguais não são estatisticamente diferentes. $\mathrm{P}=$ perto; $\mathrm{D}=$ distante; $\mathrm{C}=$ animais controle.
} 


\section{Quantidade de ductos biliares por campo em animais submetidos à hepatectomia de $70 \%$}

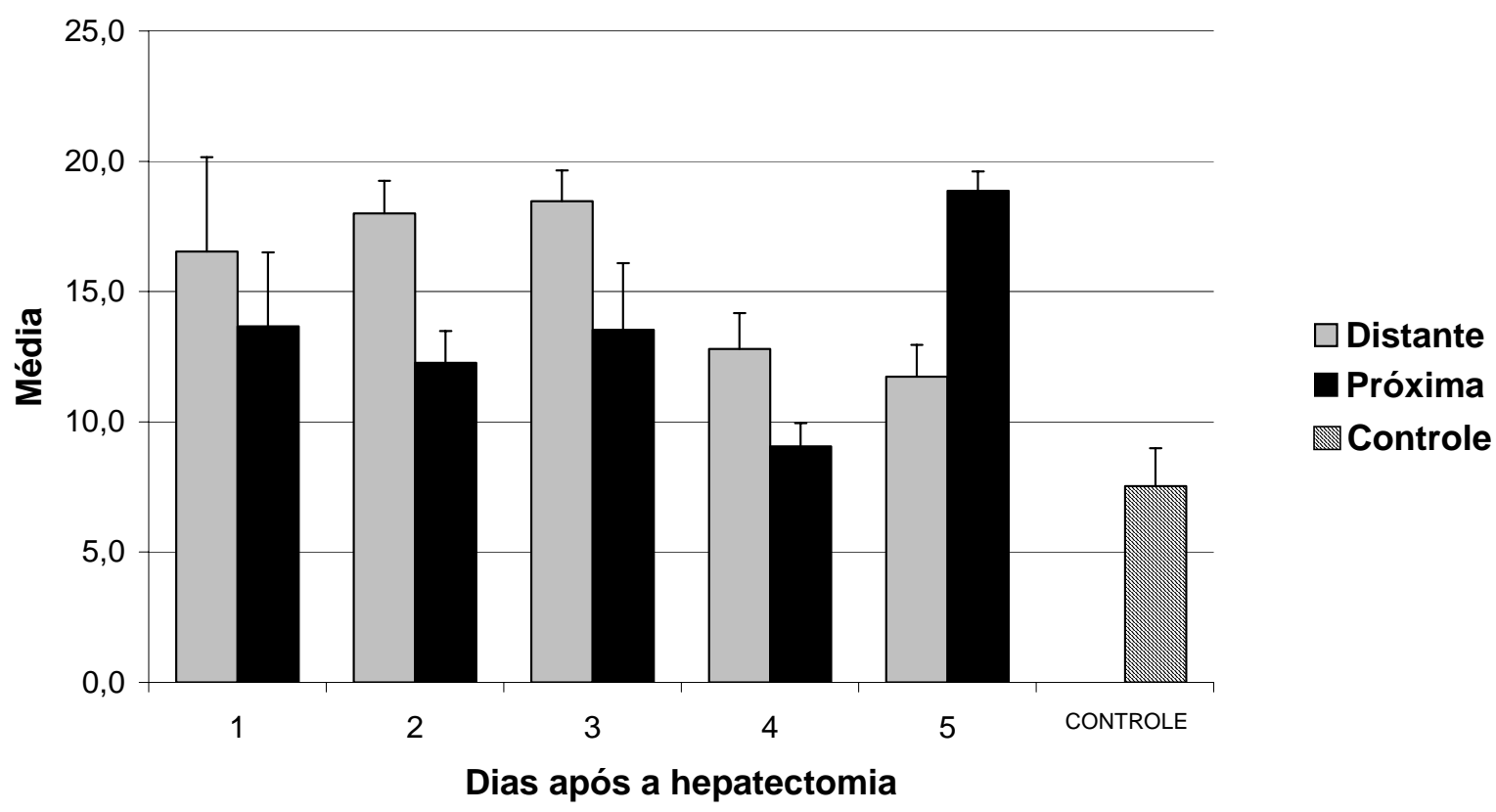

Figura 9. Gráfico comparando as médias do número de ductos biliares das regiöes distante e próxima da hepatectomia de $70 \%$. Nas regiões distante do corte, as médias são mais elevadas, à exceção da média encontrada no quinto dia.

\subsection{Citoqueratina}

\subsubsection{Hepatectomia de $30 \%$}

Depois da HP o número de células que expressam as citoqueratina AE/AE3 por campo aumenta consideravelmente (figura 10a-d). Estas células são, em sua maioria, alongadas e ramificadas, com extensos prolongamentos que correm ao longo dos cordões de hepatócitos, estendendo-se, muitas vezes, até células vizinhas com as quais fazem contato. Em grande aumento pode-se perceber ligeira marcação positiva na periferia do citoplasma dos hepatócitos, fato este não observado nos fígados dos animais controles. A cronologia dos picos assemelha-se à encontrada ao medir-se o índice de proliferação celular pela incorporação de BrdU e ao quantificar-se os ductos biliares, isto é, ocorreu 
um pico no primeiro dia tanto para as regiões próximas como para as distantes do local da incisão. Contudo, assim como observado na quantificação dos ductos biliares, a região distante da ablação apresentou maior quantidade de células por campo em todos os tempos (tabela VIII, IX e figura 11)..
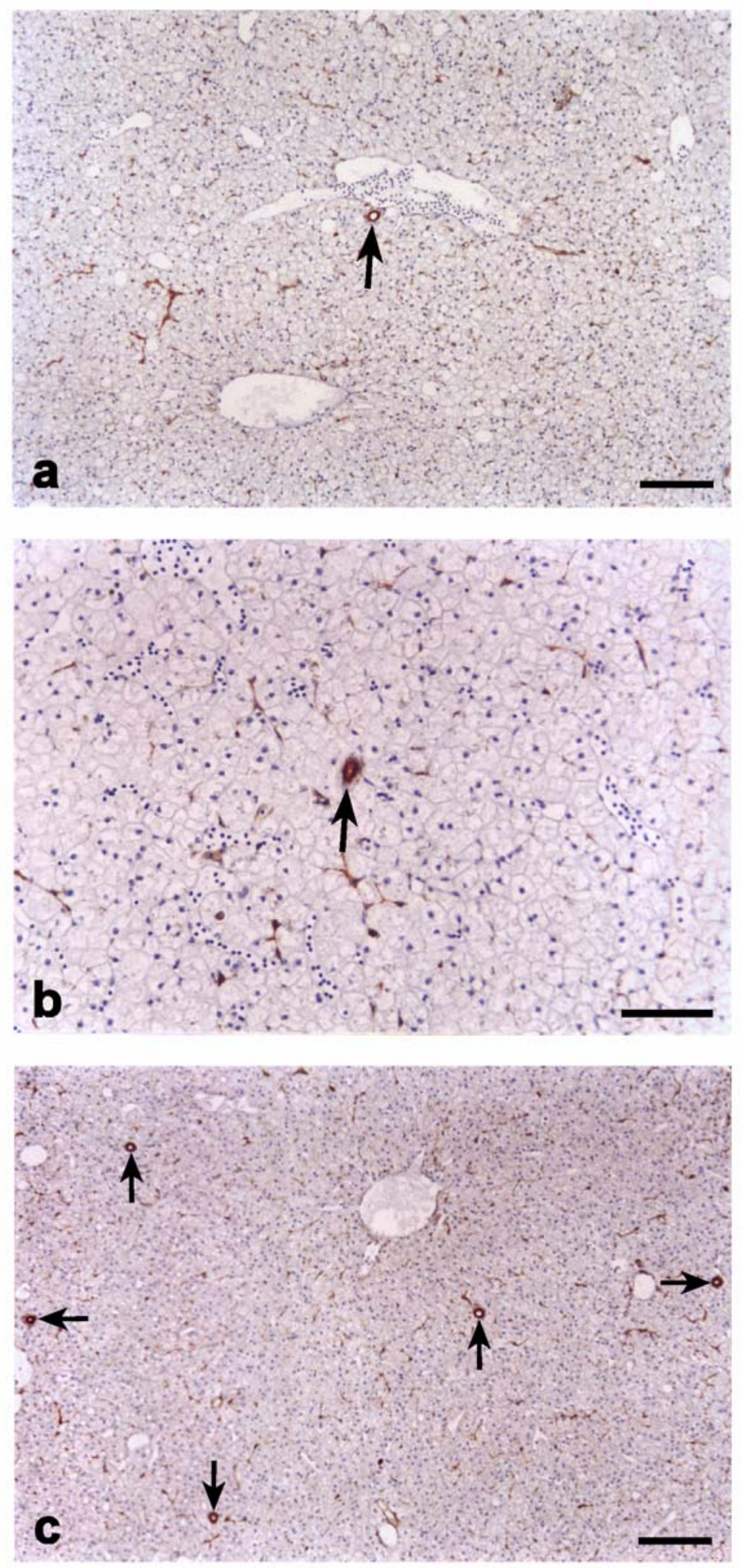
Figura 10. Fotomicrografias mostrando as células expressando as citoqueratinas AE1/AE3 reveladas pela técnica imuno-histoquímica com o método de peroxidaseDAB. a) Animal controle. As células pré-ductulares possuem um núcleo central, ao redor do qual observa-se uma reação positiva. Emitem prolongamentos que também são positivos para citoqueratina (pontas de setas). Barra $=50 \mu$. b) HP de $30 \%$, primeiro dia, região distante da incisão. Observar o aumento da quantidade de células marcadas (pontas de setas) em relação à imagem anterior e a intensificação da reação, notada em todos os animais hepatectomizados. Barra $=50 \mu$. c) HP de $70 \%$, terceiro dia, região distante da incisão. Além das células pré-ductulares, também podem são marcadas células arredondadas sem prolongamentos, as quais provavelmene são hepatócitos jovens (pontas de setas). Um ducto biliar está apontado (seta). Barra $=50 \mu$. d) HP de $70 \%$, terceiro dia, região distante da incisão. Nesta imagem, percebem-se os prolongamentos das células pré-ductulares (ponta de seta) e os hepatócitos jovens positivos à citoqueratina (seta). Barra $=30 \mu$

Tabela VIII. Média do número de células positivas à citoqueratina por campo histológico do fígados de C. gariepinus submetidos à hepatectomia parcial de $30 \%$ e de $70 \%$, nas regiões hepaticas próximas ao local da operação $(P)$ e distantes do local da operação (D) entre um a cinco dias depois da cirurgia.

\begin{tabular}{|c|c|c|c|c|c|c|c|}
\hline \multirow[b]{2}{*}{$\begin{array}{c}\text { Tipo } \\
\text { de } \\
\text { HP }\end{array}$} & \multirow[b]{2}{*}{ Local } & \multicolumn{6}{|c|}{ Dias após a hepatectomia } \\
\hline & & 0 & 1 & 2 & 3 & 4 & 5 \\
\hline \multirow{2}{*}{$30 \%$} & $\mathbf{P}$ & - & $\begin{array}{c}17,7 \pm 3,7 \\
(30)\end{array}$ & $\begin{array}{c}21,0 \pm 4,8 \\
(30)\end{array}$ & $\begin{array}{c}12,8 \pm 2,3 \\
(30)\end{array}$ & $\begin{array}{c}17,6 \pm 5,5 \\
(30)\end{array}$ & $\begin{array}{c}15,6 \pm 3,2 \\
(30)\end{array}$ \\
\hline & D & - & $\begin{array}{c}25,7 \pm 3,3 \\
(30)\end{array}$ & $\begin{array}{c}22,9 \pm 7,0 \\
(30)\end{array}$ & $\begin{array}{c}20,8 \pm 3,1 \\
(30)\end{array}$ & $\begin{array}{c}19,2 \pm 5,1 \\
(30)\end{array}$ & $\begin{array}{c}19,6 \pm 4,8 \\
(30)\end{array}$ \\
\hline \multirow{2}{*}{$70 \%$} & $\mathbf{P}$ & - & $\begin{array}{c}22,4 \pm 3,8 \\
(30)\end{array}$ & $\begin{array}{c}21,4 \pm 3,6 \\
(30) \\
\end{array}$ & $\begin{array}{c}32,0 \pm 5,6 \\
(30)\end{array}$ & $\begin{array}{c}27,0 \pm 4,4 \\
(30)\end{array}$ & $\begin{array}{c}24,3 \pm 3,6 \\
(30)\end{array}$ \\
\hline & D & - & $\begin{array}{c}24,2 \pm 6,2 \\
(30)\end{array}$ & $\begin{array}{c}23,4 \pm 4,6 \\
(30)\end{array}$ & $\begin{array}{c}32,2 \pm 4,4 \\
(30)\end{array}$ & $\begin{array}{c}33,3 \pm 3,5 \\
(30)\end{array}$ & $\begin{array}{c}32,1 \pm 4,1 \\
(30)\end{array}$ \\
\hline C & - & $\begin{array}{c}14,4 \pm \\
2,8 \\
(30)\end{array}$ & - & - & - & - & - \\
\hline
\end{tabular}

Os números representam as médias seguidas do desvio padrão, os valores entre parênteses representam o número de observações que compôem a média $(n)$. $P=$ perto; $D=$ distante; $C=$ animais controle. 
Tabela IX. Comparação do índice de células positivas a citoqueratina de regiões hepaticas próximas ao local da operação $(P)$ e distantes do local da operação (D) entre um a cinco dias depois hepatectomia parcial de $30 \%$ em C. gariepinus.

\begin{tabular}{cccccccc} 
& & \multicolumn{7}{c}{ Dias após a hepatectomia } \\
\cline { 2 - 8 } $\begin{array}{c}\text { Tipo } \\
\text { De } \\
\text { HP }\end{array}$ & Local & $\mathbf{0}$ & $\mathbf{1}$ & $\mathbf{2}$ & $\mathbf{3}$ & $\mathbf{4}$ & $\mathbf{5}$ \\
\hline & $\mathbf{P}$ & - & $\begin{array}{c}17,7 \pm 3,7 \\
(30) \mathrm{aA}\end{array}$ & $\begin{array}{c}21,0 \pm 4,8 \\
(30) \mathrm{aA}\end{array}$ & $\begin{array}{c}12,8 \pm 2,3 \\
(30) \mathrm{aB}\end{array}$ & $\begin{array}{c}17,6 \pm 5,5 \\
(30) \mathrm{aC}\end{array}$ & $\begin{array}{c}15,6 \pm 3,2 \\
(30) \mathrm{aC}\end{array}$ \\
\cline { 2 - 8 } $\mathbf{3 0 \%}$ & $\mathbf{D}$ & - & $\begin{array}{c}25,7 \pm 3,3 \\
(30) \mathrm{bA}\end{array}$ & $\begin{array}{c}22,9 \pm 7,0 \\
(30) \mathrm{aA}\end{array}$ & $\begin{array}{c}20,8 \pm 3,1 \\
(30) \mathrm{aA}\end{array}$ & $\begin{array}{c}19,2 \pm 5,1 \\
(30) \mathrm{aA}\end{array}$ & $\begin{array}{c}19,6 \pm 4,8 \\
(30) \mathrm{bA}\end{array}$ \\
\hline $\mathbf{C}$ & - & $\begin{array}{c}14,4 \pm 2,8 \\
(30)\end{array}$ & - & - & - & - & - \\
\hline
\end{tabular}

Os números representam as médias seguidas do desvio padrão, os valores entre parênteses representam o número de observações que compôem a média (n). As médias foram comparadas pelo método de comparações múltiplas de médias aos pares usando-se o teste de Tukey com alfa $<0,05$. As letras minúsculas comparam as médias nas colunas, as médias com letras iguais não são estatisticamente diferentes. As letras maiúsculas comparam as médias nas linhas, as médias com letras iguais não são estatisticamente diferentes. $P=$ perto; $D=$ distante; $\mathrm{C}=$ animais controle.

\section{Células positivas à citoqueratina por campo em animais submetidos à hepatectomia de $30 \%$}

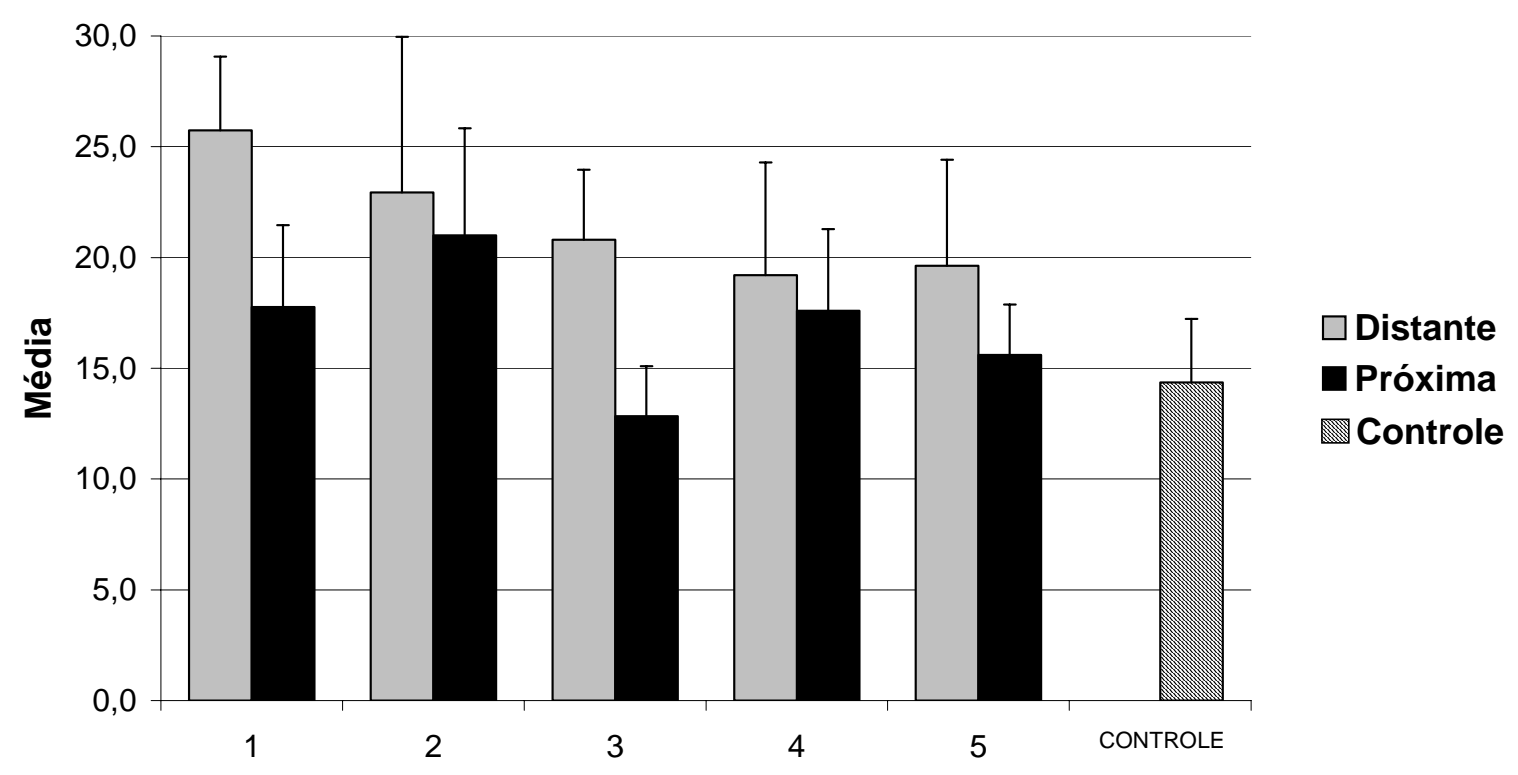

Dias após a hepatectomia

Figura 11. Gráfico ilustrando a distribuição das médias das células positivas à citoqueratina. Na hepatectomia de $30 \%$, o pico ocorre no primeiro dia na região distante e no segundo dia na região próxima. A quantidade de células é maior na região distante. 


\subsubsection{Hepatectomia de $70 \%$}

Assim como na HP de 30\%, as médias obtidas sempre foram maiores que os do controle (14,4 células por campo). Contudo, na HP de $70 \%$ as regiões distantes da zona de ablação não apresentaram índice mais elevado de células por campo que as regiões mais próximas, exceto no quarto e quinto dia. Da mesma forma que os resultados do índice de proliferação celular e da contagem de ductos biliares, os picos ocorreram no terceiro dia depois da cirurgia (média de 32 e 32,2 células por campo para a região próxima e a distante respectivamente), seguindo assim, praticamente a mesma tendência de todos os resultados (Tabela VIII, $\mathbf{X}$ e figura 10c, 12),. Os picos dos valores da HP de 70\% também são mais altos que os da HP de 30\%. Da mesma maneira que na HP de 30\%, as células que expressam as citoqueratinas AE1/AE3 são células alongadas e ramificadas em sua maioria e a expressão é mais intensa que no controle. Alguns hepatócitos, tanto na HP de 30\% como na HP de 70\% também apresentavam ligeira expressão imuno-histoquímica de citoqueratinas AE1/AE3, o que não foi observado nos animais controles. 
Tabela X. Comparação do índice de células positivas à citoqueratina de regiões hepáticas próximas ao local da operação $(P)$ e distantes do local da operação (D) entre um a cinco dias depois hepatectomia parcial de $70 \%$ em C. gariepinus.

\begin{tabular}{|c|c|c|c|c|c|c|c|}
\hline \multirow[b]{2}{*}{$\begin{array}{c}\text { Tipo } \\
\text { De } \\
\text { HP }\end{array}$} & \multirow[b]{2}{*}{ Local } & \multicolumn{6}{|c|}{ Dias após a hepatectomia } \\
\hline & & 0 & 1 & 2 & 3 & 4 & 5 \\
\hline \multirow{2}{*}{$70 \%$} & $\mathbf{P}$ & - & $\begin{array}{c}22,4 \pm 3,8 \\
(30) a A\end{array}$ & $\begin{array}{c}21,4 \pm 3,6 \\
(30) a A\end{array}$ & $\begin{array}{c}32,0 \pm 5,6 \\
(30) a B\end{array}$ & $\begin{array}{c}27,0 \pm 4,4 \\
(30) a B\end{array}$ & $\begin{array}{c}24,3 \pm 3,6 \\
(30) A b\end{array}$ \\
\hline & D & - & $\begin{array}{c}24,2 \pm 6,2 \\
(30) a A\end{array}$ & $\begin{array}{c}23,4 \pm 4,6 \\
\text { (30)aA }\end{array}$ & $\begin{array}{c}32,2 \pm 4,4 \\
(30) a B\end{array}$ & $\begin{array}{c}33,3 \pm 3,5 \\
(30) b B\end{array}$ & $\begin{array}{c}32,1 \pm 4,1 \\
(30) b B\end{array}$ \\
\hline C & - & $\begin{array}{c}14,4 \pm 2,8 \\
(30)\end{array}$ & - & - & - & - & - \\
\hline
\end{tabular}

Os números representam as médias seguidas do desvio padrão, os valores entre parênteses representam o número de observações que compôem a média (n). As médias foram comparadas pelo método de comparações múltiplas de médias aos pares usando-se o teste de Tukey com alfa $<0,05$. As letras minúsculas comparam as médias nas colunas, as médias com letras iguais não são estatisticamente diferentes. As letras maiúsculas comparam as médias nas linhas, as médias com letras iguais não são estatisticamente diferentes. $P=$ perto; $D=$ distante; $\mathrm{C}=$ animais controle.

\section{Células positivas à citoqueratina por campo em animais submetidos à} hepatectomia de $\mathbf{7 0 \%}$

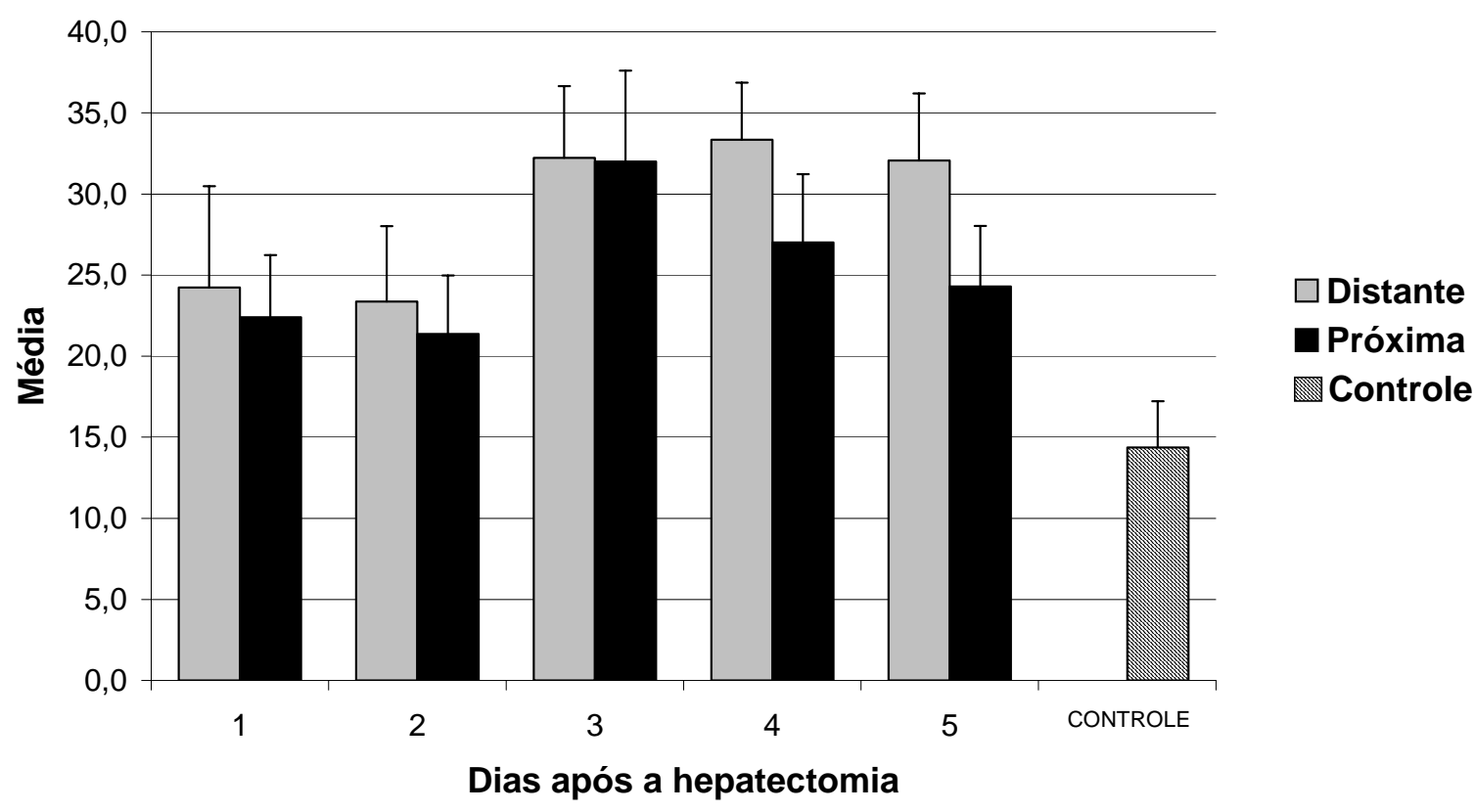

Figura 12. Gráfico ilustrando a distribuição das médias das células positivas à citoqueratina. Na hepatectomia de $70 \%$, o pico ocorre no terceiro dia na região distante e na região próxima. A quantidade de células é maior na região distante do quarto e quinto dia. 


\section{DISCUSSÃO}

\subsection{Histomorfologia}

Os animais resistiram muito bem aos procedimentos cirúrgicos. A mortalidade foi baixa, apenas dois peixes morreram, mas por causas não ligadas diretamente à cirurgia, confirmando nossa previsão de que este peixe é um bom modelo laboratorial para manipulação cirúrgica. Hampton et al. (1985) quando iniciam a discussão de seu trabalho, afirmam que, devido à diversidade de espécies de teleósteos, pode não existir um fígado cuja morfologia seja "típica". Não encontramos na literatura nenhuma descrição detalhada da histologia do fígado de Clarias gariepinus, assim inicialmente procuramos estudar este aspecto. A organização microscópica do parênquima hepático do bagre africano difere das características comumente descritas nos fígados de peixes. Nossos resultados mostram que os hepatócitos formam cordões entre os quais se observam capilares sinusóides alongados, que em corte transversal têm perfil 
arredondado. Na truta e na maioria dos teleósteos, os hepatócitos se arranjam em túbulos anastomosados e ramificados contendo de 5 a 7 hepatócitos, em cujo centro se encontra um dúctulo biliar ou células epiteliais pré-ductulares. Os sinusóides circundam os túbulos (Eurell \& Haensly, 1982; Hampton et al., 1985, 1988, 1989; Gonzalez et al., 1993; Schultz et al., 1993). Contudo, assim como em outros teleósteos, Clarias gariepinus não apresenta a distribuição de lóbulos em mosaicos formados por um espaço porta com elementos do sistema venoso, arterial e ductular e uma veia central, ramo da veia hepática. Esses elementos são encontrados freqüentemente isolados no parênquima hepático de Claria gariepinus. Dessa maneira, tornou-se difícil diferenciar os ramos da veia porta e os ramos da veia hepática. Okihiro \& Hinton (2000) observaram em truta que os ramos da veia porta apresentam uma parede mais espessa que os da veia hepática. Aplicamos então a coloração de Picrossírius, que cora prefencialmente as fibras colágenas. Este método não somente facilitou a diferenciação de ambas as estruturas, como permitiu identificar com facilidade os ductos biliares menores, os quais também apresentam um envoltório de tecido conjuntivo. As células epiteliais pré-ductulares biliares são mais difíceis de diferenciar em Clarias gariepinus, devido à disposição em placas que os hepatócitos assumem. Confundem-se com os núcleos das células endoteliais dos sinusóides, mas seu núcleo é ligeiramente maior. Em trutas, devido à orientação tubular dos hepatócitos, elas são facilmente localizadas no centro dos túbulos, lembrando as células centroacinosas do pâncreas dos mamíferos e são muito freqüentes (Okihiro \& Hinton, 2000).

Um dia após a hepatectomia, começa a haver uma dilatação dos sinusóides e desorganização dos cordões de hepatócitos, que aumenta progressivamente até o terceiro 
dia quando a arquitetura hepática começa a reorganizar-se. A morfologia do parênquima hepático e dos hepatócitos muda. Devido à intensa atividade proliferativa no fígado, confirmada pela imuno-histoquímica, os cordões são menos óbvios e o tecido apresenta amplos vasos sinusóides congestos entre os cordões de hepatócitos. Também constatamos que há um aumento de ductos biliares observáveis por campo microscópico. Porém o padrão estrutural não se restabelece até o último prazo (cinco dias) em ambas as HP. Não foram observadas diferenças importantes no tecido hepático ao compararmos as regiões distantes e próximas, ambas se apresentaram histologicamente semelhantes, qualquer que fosse o tempo decorrido depois da hepatectomia. Porém, pode ser constatado que o fígado dos animais que sofriam HP de $30 \%$ se recuperava mais rapidamente, sendo que no quinto dia estes animais tinham o parênquima hepático mais organizado que os animais que sofreram HP de $70 \%$.

\section{2. Índice de proliferação celular}

A BrdU (bromodeoxiuridina) é um análogo pirimidínico da timidina e pode ser usada para marcar o DNA das células em proliferação, sendo detectado imunohistoquimicamente com um anticorpo anti-BrdU (Gratzner, 1982). A BrdU tem sido uma ferramenta importante para os estudos da cinética celular na medicina e na oncologia (Dolbeare, 1995a, 1995b). Seu uso baseia-se na administração de um pulso de BrdU, a qual será incorporada pelo DNA das células que estejam ou que entrem na fase $\mathrm{S}$ da divisão celular durante o período entre a administração e o sacrifício do animal. A proporção de células que captaram a BrdU nesse prazo constitui o índice de proliferação celular, um valor que pode ser usado comparativamente. A comparação do índice de proliferação celular entre animais de espécie diferente exige cautela, porque, mesmo 
entre mamíferos, há diferenças relativas à espécie que podem afetar este índice. Weglarz \& Sandgren (2000), levando em conta que os hepatócitos de rato e camundongo apresentam cinéticas diferentes de síntese de DNA, demonstraram esse fato ao transplantar porções de fígado de rato em camundongos. Após hepatectomia de 70\%, os hepatócitos de camundongo e os de rato apresentaram a cinética de síntese de DNA característica de cada espécie, apesar de estarem submetidas ao mesmo ambiente.

Em teleósteos, a aplicação do índice de proliferação celular para efeitos comparativos entre as espécies, exige mais atenção ainda, devido à diferença de temperatura dos habitats dos vários peixes, diferença essa que pode interferir fortemente com o valor do índice obtido durante um período de tempo fixo. Assim, neste trabalho, fixamos a temperatura do experimento em $30{ }^{\circ} \mathrm{C}$, uma temperatura muito próxima das condições do habitat ideal de C. gariepinus para verificar o que ocorre em condições fisiológicas próximas do normal.

Neste estudo, um dos objetivos era compararar os efeitos da hepatectomia de $30 \%$ e de $70 \%$ na cinética da proliferação celular. Pelos resultados obtidos pudemos constatar que na hepatectomia de 30\% o pico de proliferação celular ocorre antes (após um dia) que na hepatectomia de 70\% (após 3 dias). No primeiro caso, cerca de 28,0\% das células se encontravam na fase S do ciclo celular após um dia, no segundo caso, cerca de $26 \%$ das células estava na fase S pós três dias.

Entre os estudo de regeneração hepática em peixes, apenas um autor mediu o índice de proliferação celular no início do processo regenerativo, o que torna difícil discutir nossos resultados comparativamente com outras espécies. Schultz et al. (1993) observaram que o pico de mitoses ocorreu após 2-3 dias em Poeciliopsis sp., porém em 
condições experimentais diferentes das que foram aqui aplicadas. Schultz et al. (1993) estimularam a regeneração hepática por lesão térmica e mantiveram os peixes a $22{ }^{\circ} \mathrm{C}$, uma temperatura mais baixa que a de nosso experimento $\left(30^{\circ} \mathrm{C}\right)$.

O pico de proliferação celular obtidos na HP de 30\% em C. gariepinus assemelhase ao encontrado em ratos submetidos à HP de 70\%, o qual ocorre em aproximadamente 20-24 horas (Werglarz \& Sandgren, 2000; Corbin et al, 2002; Mangnall et al, 2003), embora outros autores tenham encontrado um pico com 48 horas (Shimizu et al., 2001). O pico de proliferação celular obtidos na HP de 70\% em C. gariepinus assemelha-se ao encontrado em camundongos submetidos à HP de 70\%, o qual ocorre em 32-36 horas após a hepatectomia. Contudo, em ratos e camundongos, a intensidade da resposta regenerativa é proporcional à quantidade de tecido hepático removido (Michalopoulos \& DeFrances, 1997; Masson et al., 1999; Dagli, 2001), embora em camundongos não haja diferença quanto ao momento do aparecimento do pico de proliferação celular na hepatectomia de 30\% ou 70\% segundo Dagli (2001).

Ficou evidente em nosso experimento que o fígado de C. gariepinus reage à remoção de uma grande quantidade de tecido hepático pelo retardamento do pico do índice de proliferação celular, ao contrário do que ocorre em mamíferos. Este comportamento peculiar pode ser atribuído à diferença anatômica e, consequentemente, à abordagem cirúrgica do fígado durante a hepatectomia. Em mamíferos, a hepatectomia consiste na remoção de lobos inteiros do fígado com mínimos traumatismo e perda de sangue. O fígado de peixes, ao contrário do que ocorre em mamíferos, não é dividido em lobos. Assim, o procedimento cirúrgico da hepatectomia em C. gariepinus requer que se faça uma incisão através do parênquima hepático, expondo uma ampla superfície livre e 
provocando intensa hemorragia, perda de fluídos hepáticos e necrose. Quanto maior a quantidade de tecido hepático retirado, maior proporção de parênquima será comprometido e, portanto, maior a reação inflamatória, a perda de sangue e a perturbação do afluxo sanguíneo aos hepatócitos. Possivelmente o tempo mais prolongado para que o índice de proliferação celular chegue ao pico na hepatectomia de 70\% se deve ao período necessário para que o fígado e o animal se restabeleçam do traumatismo. Em apoio a esta hipótese vêm os resultados dos picos de proliferação de ductos biliares e do pico do número de células pré-ductulares, que também apareceram mais tarde nos animais que sofreram hepatectomia de 70\%.

No caso da HP de 70\%, depois do pico no terceiro dia, a atividade proliferativa diminui, sendo no quinto dia um pouco maior que a do quinto dia da HP de $30 \%$, o que pode indicar que essa regeneraçäo se prolonga por um período maior do que a da HP de 30\%. Os valores dos índices de proliferação após 24hs (aproximadamente 19\%) são mais baixos que os obtidos para ratos no mesmo período, ou seja, 29,5\% (Malik, 2002) e 46,2\% (Andiran et al.1999). A atividade em ratos é sempre maior, mesmo quando comparado os níveis durante o pico de atividade mitótica, que não é superior a 26,6\% em C. gariepinus. Esses índices refletem a diferença no tempo necessário para que a regeneração se complete os peixes, a qual é mais lenta, podendo chegar a 30 dias (Sanz et al., 1982; 1986).

No presente estudo não verificamos o tempo necessário para a completa regeneração do fígado, mas acreditamos que seja mais longa quando comparada com pequenos mamíferos como o rato e o camundongo, que o regeneram em seguida à hepatectomia de 70\% após 7-10 dias segundo Mangnall et al (2003), 7 dias segundo 
Corbin (2002) e 6-8 dias para Michalopolus (1990) ou em 10-14 dias (Higgins \& Anderson, 1931; Arias et al., 1994)

Não houve diferença nos índices de proliferação celular das regiões próximas e distantes da incisão, indicando que os estímulos para a multiplicação dos hepatócitos não são fenômenos localizados, mas sistêmicos. A regeneração hepática está diretamente relacionada com o aporte de fatores hepatotróficos pelo sangue, os quais estimulam a proliferação celular (Parra et al., 1992, 1995, 1996). Assim, uma vez que todas as partes do fígado recebam o sangue necessário para sua função, elas reagirão em sincronia aos estímulos das substâncias transportadas pelo sangue.

\subsection{Ductos biliares}

O uso das citoqueratinas AE1/AE3 como marcadoras de ductos biliares em $C$. gariepinus revelou-se bastante específico e adequado, facilitando sua visualização nos cortes histológicos, o que está de acordo com o encontrado por vários autores (Bunton, 1993, Okihiro \& Hinton, 1996, 2000). Nos fígados dos animais que sofreram hepatectomia foi observada intensa hiperplasia de ductos biliares, caracterizada por aumento de aproximadamente $146 \%$ no número de ductos por campo nos picos. O aumento da quantidade de ductos biliares após hepatectomia parcial também foi descrito em mamíferos (Fishback, 1929; Oren et al., 1998) e em truta (Okihiro \& Hinton, 2000). O pico de presença de ductos biliares coincidiu com os picos de proliferação celular, isso quer dizer, um dia para HP de $30 \%$ e três dias para HP de $70 \%$, regredindo o número após o pico, chegando aos cinco dias com mais ou menos o dobro de ductos em comparação ao controle. Essa semelhança também foi observada em cães, nos quais o aumento de ductos biliares se dá com seis dias, sendo que o pico de proliferação celular 
nos mesmos acontece entre o terceiro e sexto dia (Fishback, 1929). Já Schultz et al. (1992) não observaram aumento do número de ductos no fígado em regeneração do peixe Poeciliopsis sp., salientando-se, porém, que estes autores utilizaram temperatura subletal para causar a lesão hepática e estimular o processo regenerativo, ao invés da hepatectomia parcial. No caso de C. gariepinus, provavelmente a proliferação de ductos biliares procura acompanhar o aumento da quantidade de hepatócitos, restruturando a rede de drenagem biliar, que precisa ser ampliada devido à hiperplasia compensatória do parênquima hepático que foi estimulada pela hepatectomia.

A hiperplasia foi mais intensa nas regiões distantes do local da incisão, não importando a quantidade de tecido retirado, isto é, seja HP de $30 \%$ ou HP de $70 \%$. É possível que fatores que se difundiram da região com células em degeneração próximas ao local da incisão tenham interferido com a proliferação dos ductos, embora isto seja apenas uma hipótese que precisa ser confirmada por mais experimentos. Também parece haver uma tendência ao aumento do número de ductos após o quinto dia em todos os tempos e regiões estudados.

\subsection{Citoqueratinas}

Neste experimento, verificamos que no fígado dos animais controles, apenas dois tipos celulares expressam as citoqueratinas AE1/AE3: as células do epitélio dos ductos biliares e as células delgadas e ramificadas entre os cordões dos hepatócitos. Pela sua localização e morfologia, estas últimas são as células epiteliais pré-ductulares biliares (CEPDBs). O aumento de seu número nos animais hepatectomizados confirma sua identidade e as equipara às células ovais dos mamíferos, conforme discutido a seguir. 
Os picos da quantidade de células expressando citoqueratinas AE1/AE3 na hepatectomia de 30\% (no primeiro e segundo dia) e de 70\% (terceiro e quarto dia) coincidiram com os picos de células positivas à BrdU e com os da quantidade de ductos biliares. A região distante da incisão apresentou ligeira tendência a apresentar maior quantidade de células reativas que a região próxima. Em truta, Okihiro \& Hinton (2000) observaram o contrário, ou seja, a diminuiçäo de células positivas à citoqueratina à medida que a distância da região de hepatectomia aumenta. Entretanto, as observações daqueles autores foram feitas a partir de uma semana depois da hepatectomia, a qual foi apenas de 6\%. Em C. gariepinus, após o terceiro dia da hepatectomia não se observa uma tendência de redução acentuada do número de células marcadas, existindo a possibilidade de que esse quadro continue ainda por algum tempo ou se modifique.

Em mamíferos foi demonstrado que os próprios hepatócitos e as células ovais podem dar origem a novos hepatócitos. As células ovais por sua vez podem se originar a partir de células-tronco hematopoéticas e de células situadas nos canais de Hering, na região terminal dos ductos biliares (Ankoma, 1999; Shafritz \& Dabeva., 2002). Contudo, sua participação na restauração do parênquima hepático em mamíferos parece ser mais importante na injúria tóxica, carcinogênese ou necrose maciça do fígado. Seu papel no processo regenerativo após hepatectomia parcial experimental parece ser bastante reduzido (Vessey \& de la Hall, 2001; Fausto \& Campbell, 2003; Mangnall et al., 2003).

Nos peixes teleósteos, mesmo tendo em vista as diferenças de organização estrutural do fígado e seus componentes, as células que mais se assemelham às células ovais dos mamíferos, tanto morfologicamente, enzimaticamente como imunohistoquimicamente, são as células epiteliais pré-ductulares biliares (CEPDBs), as quais 
expressam as citoqueratinas AE1/AE3 (Hampton et al., 1988; Okihiro \& Hinton, 2000). Assim como em truta, em C. gariepinus, as CEPDBs proliferam depois do estímulo desencadeado pela hepatectomia, sendo que esse estímulo parece ter sido mais intenso na HP de 70\%, embora tenha havido um retardo no aparecimento do pico. A coincidência do pico do índice de proliferação celular dos hepatócitos, do pico de proliferação de ductos biliares e de CEPDBs expressando citoqueratina em ambos os tipos de hepatectomia em C. gariepinus sugere que estas estruturas estão sujeitas a estímulos semelhantes. Ainda, o fato de que os três tipos celulares (hepatócitos jovens, células epiteliais dos ductos biliares e CEPDBs) expressam as citoqueratinas também sugere, ainda que indiretamente, que estas células estão estreitamente relacionadas e que têm uma origem comum (Germain et al., 1988; Bunton, 1993; Okihiro \& Hinton, 2000).

\section{5.. Comentários finais e conclusão}

Ambos os procedimentos que envolveram a remoção de $30 \%$ ou de $70 \%$ do fígado de C. gariepinus foram suficientes para gerar um estímulo de regeneração compensadora e proliferação celular pelo menos três vezes superior ao encontrada nos animais controles. Embora o índice de proliferação celular fosse semelhante nos picos em ambos os casos, o pico do índice de proliferação celular da HP de 70\% foi atingido dois dias depois do pico da HP de 30\%, o que atribuímos ao sério traumatismo, perda de sangue e choque decorrente da amputação, tendo em vista que o fígado de C. gariepinus não é dividido em lobos como nos mamíferos. Essa conclusão é reforçada pelo retardo do aparecimento dos outros parâmetros estudados, como a proliferação de ductos e de CEBPDs , na HP de 70\%. Concluímos que, para os estudos envolvendo a regeneração ou efeito de substâncias carcinógenas em fígado de C. gariepinus e que requeiram um 
estímulo regenerativo, a HP de 30\% é um procedimento que gerará uma hiperplasia compensadora suficiente e facilmente mensurável do fígado, sem o traumatismo inerente a uma HP de 70\%. Fundamentamos esta conclusão na constação de que existe pouca diferença entre os picos dos três parâmetros medidos quando é levada em conta a quantidade de tecido removido, seja 30\% ou 70\%. Contudo, os valores dos picos são bastante superiores ao controles, e portanto, de fácil detecção. Ademais, sendo a HP de 30\% menos traumática para o animal, os picos ocorrem antes do que na HP de $70 \%$ e os eventos regenerativos sofrem menos interferência do estado geral do peixe. Julgamos também que a temperatura em que os peixes permaneceram durante o experimento, de 30 ${ }^{\circ} \mathrm{C}$, pode ter acelerado os processos regenerativos e pode explicar a diferença entre o pico do índice de proliferação encontrado nesta e em outras espécies.

Em relação ao local onde é colhida a amostra de tecido, embora não houvesse diferença quanto ao índice de proliferação celular, a região distante da incisão mostrou-se mais ativa em relação à região próxima na proliferação de ductos biliares e de CEBPDs em ambos os tipos de hepatectomia. Assim, concluímos que as amostras de fígado devem ser colhidas nas regiões distantes da hepatectomia em C. gariepinus caso o objetivo seja estudar eventos relacionados com a proliferação dessas duas estruturas na primeira semana.

Assim como em outros peixes, a regeneração do fígado de C. gariepinus após hepatectomia parcial provoca hiperplasia e hipertrofia das células epiteliais préductulares biliares, as quais são funcionalmente semelhantes às células ovais dos mamíferos e parecem ser para os peixes teleósteos o equivalente à célula tronco hepática dos mamíferos. A constatação de que os hepatócitos nos animais controles não expressam 
citoqueratinas, as quais estão presentes em pequena quantidade no citoplasma de hepatócitos jovens após a hepatectomia parcial sugere também que CEBPDs estão se diferenciando em hepatócitos, os quais perdem progressivamente a expressão de citoqueratinas à medida que amadurecem. 


\section{Conclusões}

1. A velocidade e a intensidade com que ocorre a hiperplasia compensatória após a hepatectomia parcial no fígado de Claria gariepinus medida pelo índice de proliferação celular está diretamente relacionada à quantidade de tecido hepático retirado.

2. A velocidade e a intensidade da hiperplasia compensatória após a hepatectomia parcial no fígado de Claria gariepinus é uniforme em todo o fígado, não havendo diferença entre a região próxima ou distante da incisão.

3. Os eventos regenerativos relacionados com a proliferação de ductos biliares e células epiteliais pré-ductulares biliares são menos intensos na região próxima à zona onde o tecido foi removido tanto na HP de 30\% como na HP de 70\%. 


\section{REFERÊNCIAS BIBLIOGRÁFICAS}

ANDIRAN, F.; AYHAN, A; TANYEL, F.C.; ABBASOGLU, O; SAYEK I. Regenerative capacities of normal and cirrhotic liver following 70\% hepatectomy in rats and the effect of atocopherol on cirrhotic regeneration. Journal of Surgical Research, 89:184-188, 2000.

ANKOMA-SEY, V. Hepatic regeneration - Revisiting the myth of Prometheus. New Physiol. Sci., 14:149-155, 1999.

ARIAS, I. M.; BOYER, J. L.; FAUSTO, N.; JAKOBY, W. B.; SCHACHTER, D.; SHAFRITZ, D. A. The liver: biology and pathobiology. 3rd. New York:Raven Press, 1994. 1628 p.

BUNTON, T. E. The immunohistochemistry of cytokeratin in fish tissues. Veterinary Pathology 30:418-425, 1993.

CHAPMAN, G. B. Ultrastructure of the liver of the fingerling rainbow trout (Salmo gairdneri), Richardson. J. Fish. Biol., 18: 553-567, 1981.

CORBIN, I. R.; BUIST, R.; VOLOTOVSKYY, V.; PEELING, J.; ZHANG, M.; MINUK, G. Y. Regerative activity and liver function following partial hepatectomy in the rat using ${ }^{31} \mathrm{P}$ - MR Spectroscopy. Hepatology, 36, 2:345-353, 2002. 
DESBARATS, J.; NEWELL, M. K. - Fas engagement accelerates liver regeneration after partial hepatectomy. Nature Medicine, 6:920-923, 2000.

DOLBEARE, F. Bromodeoxyuridine: a diagnostic tool in biology and medicine, Part I: Historical perspectives, histochemical methods and cell kinetics. Histochemical Journal, 27:339-369, 1995a.

DOLBEARE, F. Bromodeoxyuridine: a diagnostic tool in biology and medicine, Part II: Oncology, chemotherapy and carcinogenesis. Histochemical Journal, 27:923-964, 1995b.

EURELL, J.A.; HAENSLY, W. E. The histology and ultrastructure of the liver of atlantic croaker Micropogon undulatus L. J. Fish Biol. 21:113-125, 1982.

FAA, G.; VAN EYKE, P.; ROSKAMS, T.; MIYAZAKI, H.; SERRELI, S.; AMBU, R.; DESMET, V. J. Expression of Cytoqueratin 20 in Developing Rat Liver and in Experimental modwla of Ductular an Oval Cell Proliferation. Journal of Hepatology, 29: 628-633, 1998.

FABRI, E.; BUZZI, M.; BIONDI, C.; CAPUZZO, A. aAdrenoceptor-mediated glucose release from perifused catfish hepatocytes. Life Sciences, 65:27-35, 1999.

FAUSTO, N.; CAMPBELL, J. S. - The role of hepatocytes and oval cells in liver regeneration and repopulation. mechanisms of development, 120:117-130, 2003.

FISHBACK, F. C. - A morphologic study of regeneration of the liver after partial removal. Archives of Pathology, 7:955-977,1929

GERMAIN, L.; BLOUIN, M.; MARCEAU, N. Differential cytokeratin and alpha fetoprotein expression in morphologically distinct epithelial cells emerging at the early stages of rat hepatocarcinogenesis. Cancer Res 45:673-681, 1985.

GONZALEZ, G.; CRESPO, S.; BRUSLE, J. Histo-cytological study of the cabrilla sea bass, Serranus cabrilla (Teleostei, Serranidae). Journal of fish Biology:363-373, 1993

GOODWIN, A. E.; GRIZZLE, M. J. Oncogene expression in hepatic and biliary neoplasms of the fish Rivulus ocellatus marmoratus: Correlation with histologic changes. Carcinogenesis, 15:1993-2002, 1994.

GOODWIN, A. E.; GRIZZLE, M. J. Oncogene expression in hepatocytes of the fish Rivulus ocellatus marmoratus: During the necrotic and regenerative phases of diethylnitrosamine toxicity. Carcinogenesis, 15:1985-1992, 1994

GROFF, J. M.; HINTON, D. E.; McDOWELL, T. S.; HEDRICK, R. P. - Progression and resolution of megalocytic hepatopathy with exocrine pancreatic metaplasia in a population of cultured juvenile striped bass Morone saxatilis. Diseases of Aquatic Organisms, 13:189-202, 1992. 
HAMPTON, J. A.; Mc-CUSKEY, P. A.; Mc-CUSKEY, R. S.; HINTON D. E. Functional units in rainbow trout (Salmo gairdneri) liver I. Arrangement and histochemical properties of hepatocytes. The Anatomical Record, 213:166-175, 1985.

HAMPTON, J. A;. LANTZ, R. C.; GOLDBLATT, P. J.; LAUREN, D. J.; HINTON D. E. Functional units in rainbow trout (Salmo gairdneri Richardson.) liver II. The biliary system. The Anatomical Record, 221:619-635, 1988.

HAMPTON, J. A;. LANTZ, R. C.; HINTON D. E. - Functional units in rainbow trout (Salmo gairdneri Richardson.) liver III. Morphometric analysis of parenchima, stroma, and component cell types. The American Journal of Anatomy, 185:58-73, 1989.

HENDRICKS, J. D.; MEYERS, T. R.; SHELTON, D. W. Histological progression of hepatic neoplasia in rainbow trout (Salmo gairdneri). National Cancer Institute Monograph, 65; 321-336, 1981.

HIGGINS, G. M.; ANDERSON, R. M. Experimental pathology of the liver. I. Restoration of the liver of the white rat following partial surgical removal. Archives of Pathology, 12:186-202, 1931.

HINTON, D. E.; POOL, C. R. Ultrastructure of the liver in channel catfish Ictalurus punctatus (Rafinesque). J. Fish. Biol., 8: 209-219, 1976.

HINTON, D. E.; SNIPES, R. L. ; KENDALL, M. E. Morphololy and enzime histochemistry in the liver of largemouth bass (Micropterus salmoides). Journal Fisheries Research Board of Canada, 29:531-534, 1972.

KENDALL, M. W.; HAWKINS, W. E. Hepatic morphology and acid phosphatase localization in the channel catfish (Ictalurus punctatus). J. Fish. Res. Board Can. 32:159-1464, 1975.

KöHLER, A. Regeneration of contaminant-induced liver lesions in flounder experimental studies towards the identification of cause-effect relationships. Aquatic Toxicology, 14:203-232, 1989.

KOZA, R. A.; MOORE, M. J. ; STEGEMAN, J. J. - Elevated ornithine decarboxylase activity, polyamines and cell proliferation in neoplastic and vacuolated liver cells of winter flounder ( Pleuronectes americanus). Carcinogenesis, 14: 399-405, 1993.

MALIK, R.; MELLOR, N.; SELDEN, C.; HODGSON, H. Triiodothyronine enhances the regenerative capacity of the liver following partial hepatectomy. Hepatology, 37:7986, 2003. 
MANGNALL, D.; BIRD. N. C.; MAJEED, A. W. The molecular physiology of liver regeneration following partial hepatectomy. Liver International, 23:124-138, 2003.

MARCEAU, N.; BLOUIN, MJ.; GERMAIN, L.; NOEL M. Role of different epithelial cell types in liver ontogenesis, regeneration and neoplasia. In Vitro Cellular and Developmental Biology, 25: 336-341, 1989.

MICHALOPOULOS, G. K. ; DEFRANCES, M. C. Liver regeneration. Science, 276:6066, 1997.

OKIHIRO, M. S.; HINTON, D. E. Enzyme histochemical characterization of hepatic regeneration following partial hepatectomy in medaka Oryzias latipes. Marine Enviromental Research, 42: 110-111, 1996.

OKIHIRO, M. S.; HINTON, D. E. - Partial hepatectomy and bile duct ligation in rainbow trout (Oncorhynchus mykiss): Histologic, immunohistochemical and enzyme histochemical characterization of hepatic regeneration and biliary hyperplasia. Toxicologic Pathology, 28:342-356, 2000.

OREN, R.; RESNICK, M.B.; BRIL,L S; DOTAN, I.; ZAIDEL, L.; LIFSHITSMERCER, B.; HALPERN, Z. Thyroxine accelerates proliferation of injured liver cells. J Hepatol., 29(4):634-647, 1998.

PARRA, O. M.; HERNANDEZ-BLASQUEZ, F. J.; CUNHA DA SILVA, J. R. M.; SOUSA SILVA, R. A. P.; SAAD, W. A., SAAD JUNIOR, W. A. Behavior of collagen extracellular liver matrix during regenerative growth after partial hepatectomy or after stimulation by exogenous hepatotrophic factors. Study in rats. Arquivos de Gastroenterologia, 33: 212-216, 1996.

PARRA, O. M.; SAAD, W. A.; FERRAZ NETO, J. B. E.; FERRI S.; SILVA, R. A. P. S.; DAL COLLETTO, G. M. D.; SAAD JUNIOR, W. A. Additional growth of an intact liver induced by exogenous hepatotrophic factors: a study in rats. Arquivos Brasileiros de Cirurgia Digestiva, 7: 64-68, 1992.

PARRA, O. M.; SILVA, R. A. P. S.; SILVA, J. R. M. C.; HERNANDEZ-BLASQUEZ, F. J.; PEDUTO, L.; SAAD, W. A.; SAAD JUNIOR, W. A. Enhancement of liver size by stimulation of intact rat liver with exougenous hepatotrophic factors. Revista Paulista de Medicina, 113: 941-947, 1995.

PASANTES, J. J.; MARTINEZ-EXPOSITO, M. J.; TORREIRO, A.; MENDEZ, J. The sister chromatic exchange test as an indicator of marine pollution: some factors affetcting sce frequencies in Mytilus galloprovincializ. Marine Ecology Progress Series, 143:113-119, 1996.

SANZ, A.; GARCIA, M.; CARDENETE, G.; ZAMORA, S. - Hepatectomy in rainbow trout (Salmo gairdneri). A preliminary study. Comp. Biochem. Physiol. 71A:329-332, 1982. 
SANZ, A.; HIDALGO, M. C.; CARDENETE, G; GARCIA, M.;. DE LA HIGUERA, M. Some functional consequences of partial hepatectomy in rainbow trout (Salmo gairdneri). Biochem. Physiol., 83A:213-215, 1986

SCHULTZ, R. J.; KAPLAN, L. A. E.; SCHULTZ, M. E. Heat induced liver cell proliferation in livebearing fish Poeciliopsis. Environmental Biology of Fishes, 36:83-91, 1993

SHAFRITZ, D. A.; DABEVA, M. D. Liver stem cells and model systems for liver repopulation. Journal of Hepatology, 36:552-564, 2002.

SHIMIZU, H.; MIYAZAKI, M.; WAKBAYASHI, Y.; MITSUHASHI, N.; KATO, A.; ITO, H.; NAKAGAWA, K.; YOSHIDOME, H.; KATAOKA, M.; NAKAJIMA, N. Vascular endothelial growth factor secreted by replicating hepatocytes induces sinusoidal endothelial cell proliferation during regeneration after partial hepatectomy in rats, Journal of Hepatology, 34: 683-689, 2001

VESSEY, C. J.; de LA HALL, P.M. Hepatic stem cells: A review. Pathology, 33: 130141, 2001.

WEGLARZ, T. C.; SANDGREN, E. P. Timing of hepatocyte entry into dna synthesis after partial hepatectomy is cell autonomus. Proc. Nati. Acad. Sci. Usa,. 97:1259512600, 2000. 